\title{
The links between the Madden-Julian Oscillation and European weather regimes
}

\author{
Joshua Chun Kwang Lee ${ }^{1,2}$ (D) $\cdot$ Robert William Lee ${ }^{3}$ (D) Steven James Woolnough ${ }^{3}$ (D) Luke John Boxall ${ }^{4}$ (D
}

Received: 12 April 2019 / Accepted: 7 April 2020/Published online: 5 May 2020

(C) The Author(s) 2020

\begin{abstract}
Skillful weather forecasting on sub-seasonal timescales is important to enable users to make cost-effective decisions. Forecast skill can be expected to be mediated by the prediction of atmospheric flow patterns, often known as weather regimes, over the relevant region. Here, we show how the Grosswetterlagen (GWL), a set of 29 European weather regimes, can be modulated by the extra-tropical teleconnection from the Madden-Julian Oscillation (MJO). Together, these GWL regimes represent the large-scale flow characteristics observed in the four North Atlantic-European classical weather regimes (NAE-CWRs), while individually capturing synoptic scale flow details. By matching each GWL regime to the nearest NAE-CWR, we reveal GWL regimes which occur during the transition stages between the NAE-CWRs and show the importance of capturing the added synoptic detail of GWL regimes when determining their teleconnection pattern from the MJO. The occurrence probabilities of certain GWL regimes are significantly changed 10-15 days after certain MJO phases, exhibiting teleconnection patterns similar to their NAE-CWR matches but often with larger occurrence anomalies, over fewer consecutive MJO phases. These changes in occurrence probabilities are likely related to MJO-induced changes in the persistence and transition probabilities. Other GWL regimes are not significantly influenced by the MJO. These findings demonstrate how the MJO can modify the preferred evolution of the NAE atmospheric flow, which is important for sub-seasonal weather forecasting.
\end{abstract}

Keywords Madden-Julian Oscillation · Grosswetterlagen $\cdot$ Teleconnections $\cdot$ Weather regimes $\cdot$ Sub-seasonal $\cdot$ Synoptic

Electronic supplementary material The online version of this article (https://doi.org/10.1007/s00704-020-03223-2) contains supplementary material, which is available to authorized users.

Joshua Chun Kwang Lee

joshua_lee@nea.gov.sg

Robert William Lee

r.w.lee@ reading.ac.uk

Steven James Woolnough

s.j.woolnough@reading.ac.uk

Luke John Boxall

lboxall@met-set.com

1 Department of Meteorology, University of Reading, Reading, UK

2 Present address: Centre for Climate Research Singapore, Meteorological Service Singapore, Singapore, Singapore

3 Department of Meteorology, National Centre for Atmospheric Science, University of Reading, Reading, UK

4 MetSet Ltd, Alton, UK

\section{Introduction}

Skillful weather forecasting in the North Atlantic-European (NAE) region on sub-seasonal timescales provides useful information with sufficient lead time for end-users in various sectors to make cost-effective decisions (Soares et al. 2018). These sectors often require quantitative estimates of certain parameters associated with the weather. Parameters such as wind and solar irradiance vary temporally and spatially over the NAE region and may influence the energy sector (Heide et al. 2010; Bloomfield et al. 2016; Cannon et al. 2017; Grams et al. 2017; Santos-Alamillos et al. 2017), while precipitation and temperature may influence the agriculture and forestry sectors (Scheifinger et al. 2003; Maracchi et al. 2005; Kirilenko and Sedjo 2007; Lavalle et al. 2009). Strong correlations usually exist between these weather parameters and the dynamical circulation patterns over the region (Plaut and Simonnet 2001; Santos et al. 2005; Ullmann et al. 2014), highlighting the value of improvement in the prediction of NAE dynamical circulation patterns. 
The NAE large-scale dynamical circulation patterns are often described as NAE weather regimes, and various methods have been used to characterise and classify these patterns. This is not straightforward, given that the patterns develop continuously with time. Weather regimes may be defined objectively by deploying a numerical method to generate a finite set of regimes based on these patterns. When defining weather regimes, Michelangeli et al. (1995) suggested considering three general properties: recurrence, persistence or quasi-stationarity. Recurrence implies that certain large-scale circulation patterns occur frequently, and a set of weather regimes can be found by cluster analysis. Persistence implies that certain large-scale circulation patterns persist, and a set of weather regimes can be found by identifying various anomaly patterns that persist beyond a threshold duration, although determining the optimal threshold may be subjective. Quasi-stationarity implies that large-scale circulation patterns reach certain non-linear equilibrium states perturbed by synoptic fluctuations (Reinhold and Pierrehumbert 1982). Using these three properties, Michelangeli et al. (1995) found that the optimal number of weather regimes was four during the boreal winter in the NAE region, hereafter referred to as the classical weather regimes (NAE-CWRs). These comprise the negative North Atlantic Oscillation (NAO-), positive North Atlantic Oscillation (NAO+), Atlantic ridge (AR) and Scandinavian blocking (SB). It should be noted that the NAO patterns are consistent but not identical to the definition using the principal component-based NAO index since they are not exact opposites, nor are they orthogonal to AR or SB.

Recent attempts have been made to improve the subseasonal forecast of the NAE-CWRs, by utilising potential sources of predictability such as slow-varying Earth system processes or quasi-oscillatory weather phenomena (Vitart 2014). In particular, recent studies (Cassou 2008; Lin et al. 2009; Yadav and Straus 2017) have shown that the MaddenJulian Oscillation (MJO), a dominant source of sub-seasonal predictability, can influence the NAE large-scale circulation patterns. Other studies investigate the modulation of extratropical atmospheric variability and extreme event frequency and intensity by the enhanced convection associated with the MJO (Ferranti et al. 1990; Jones 2000; Vecchi and Bond 2004; Mori and Watanabe 2008; Casanueva et al. 2014; Matsueda and Takaya 2015).

The enhanced convection associated with the MJO acts as a forcing which initiates tropical circulation anomalies; it can be viewed as a mass source in the upper troposphere which results in upper tropospheric horizontal divergence (Kiladis and Weickmann 1992). This contributes to the Rossby wave source, given by the sum of the vorticity advection by the divergent wind and upper tropospheric horizontal divergence (Sardeshmukh and Hoskins 1988). Once the Rossby wave source reaches the subtropical regions, vorticity anomalies occur within the subtropical jet and are guided by the mean westerly flow (Matthews et al. 2004). The vorticity anomalies within the jet can initiate a poleward propagating Rossby wave train over the Pacific and Atlantic. Hoskins and Ambrizzi (1993) used a barotropic model to demonstrate how a localised divergence forcing at the equator can eventually lead to the propagating Rossby wave train. The timescale by which the extra-tropical flow is modified by the propagating Rossby wave train depends on the initialised location of the Rossby wave source, which is closely linked to the MJO phases since both are sensitive to the longitudinal position of the enhanced convection. Given a propagating MJO, the extra-tropical response would then be the sum of responses to the enhanced convection over different locations, with different time lags (Stan et al. 2017).

The propagating Rossby wave train is an important teleconnection mechanism for the extra-tropical response in the NAE region (Cassou 2008; Lee et al. 2019), which occurs through dominant synoptic scale Rossby wave breaking (RWB) along the dynamical tropopause. A similar teleconnection mechanism occurs in the stratosphere, with heat and momentum flux transfer between the troposphere and the stratospheric polar vortex (Garfinkel et al. 2014; Lee et al. 2019). These teleconnections affect the position and orientation of the jet stream (Rivière and Orlanski 2007), mid-latitude blocking frequency (Woollings et al. 2008; Masato et al. 2012) and are related to the maintenance and formation of the NAE large-scale circulation patterns (Benedict et al. 2004; Vallis and Gerber 2008; CharltonPerez et al. 2018; Lee et al. 2019). Rossby wave trains propagate along jet streams due to their faster speeds, reaching the critical latitude (where waves become stationary relative to the background flow; Hoskins and Karoly 1981; Hoskins and Ambrizzi 1993). The critical latitude determines where the waves turn equatorward, and consequently the location of RWB events, which strongly influences the resulting weather regimes that develop. Rossby waves can undergo either cyclonic or anticyclonic wave breaking (CWB and AWB; Thorncroft et al. 1993), typically at the poleward side and equatorial side of the climatological jet respectively (Swenson and Straus 2017). AWB events in the Eastern Atlantic are typically associated with a $\mathrm{NAO}+$ signal (Benedict et al. 2004; Swenson and Straus 2017), and AR and SB NAE-CWRs are often collocated with AWB occurrences. By contrast, $\mathrm{CWB}$ events are often associated with a NAO- signal, with increased CWB occurrences in the Eastern Atlantic (Benedict et al. 2004; Swenson and Straus 2017).

As RWB events often occur on synoptic scales, these details need to be captured to present a more complete picture of the smooth development and evolution of the flow patterns both climatologically and under the MJO influence. The NAE-CWRs capture the large-scale flow characteristics over the NAE region, but they are not so detailed on the synoptic 
scale. An extension to seven weather regimes, employed by Grams et al. (2017), captures more details of the large-scale flow pattern, but still does not capture many of the synoptic scale details. Neal et al. (2016) defined 30 weather patterns and demonstrated the usefulness of capturing synoptic scale details in medium-range forecasting. A weather regime classification system that is similarly designed to focus on the synoptic scale is the Grosswetterlagen (GWL). The subjective GWL catalogue was first conceived by Baur et al. (1944) and improved by Hess and Brezowsky (1952, 1969, 1977). It was further updated by Gerstengabe et al. (1999) and is since maintained by the Deutscher Wetterdienst (DWD). James (2007) first developed an objective method using a pattern correlation technique to create a GWL catalogue with weather regimes defined based on the properties of recurrence and persistence. The NAE large-scale circulation patterns are classified into 29 identifiable weather regimes instead of four, with a primary focus on Central Europe. These 29 weather regimes follow an intuitive naming convention which is meaningful for understanding the flow characteristics and are listed in Table 1.

Previous studies have documented the MJO teleconnection patterns with the NAE-CWRs (e.g. Cassou 2008; Lin et al. 2009), based on the RWB mechanism. However, finer teleconnection details associated with localised differences in the flow pattern may not be well captured when using only four NAE-CWRs and may be revealed when using $29 \mathrm{GWL}$ regimes which sufficiently accounts for these localised differences. Here, we present evidence of interaction between the MJO and the GWL. The data and statistical methods employed in this study are described in Section 2. The matching of $29 \mathrm{GWL}$ regimes to four NAE-CWRs is performed in Section 3. Lagged composites showing the interaction between the MJO phases and GWL regimes are presented in Section 4. The possible reasons behind any changes in the frequencies of GWL regimes due to MJO forcing are explored in Section 5, and conclusions are presented in Section 6.

\section{Data and methods}

The GWL time series is a daily 1979-2018 index of GWL regimes, provided by MetSet (this time series is downloadable as a supplementary file). The numerical method, reanalysis dataset, data fields and algorithm for the classification are commercially sensitive. The index follows the 29 GWL regimes described in Table 1, based on an objective method of classifying the NAE large-scale circulation patterns. This method is designed to best match the original subjective GWL catalogue, but does not factor in persistence.

The MJO is represented using the daily real-time multivariate MJO (RMM) index of Wheeler and Hendon (2004), obtained from the Australian Bureau of Meteorology for 1979-
Table 1 The 29 Grosswetterlagen (GWL) regimes with the translated definition from German to English

\begin{tabular}{ll}
\hline GWL & English translation of synoptic pattern definition \\
\hline WZ & Anticyclonic westerly \\
WA & Cyclonic westerly \\
WS & South-shifted westerly \\
WW & Maritime westerly (block Eastern Europe) \\
SWA & Anticyclonic south-westerly \\
SWZ & Cyclonic south-westerly \\
NWA & Anticyclonic north-westerly \\
NWZ & Cyclonic north-westerly \\
HM & High over Central Europe \\
BM & Zonal ridge across Central Europe \\
TM & Low (cutoff) over Central Europe \\
NA & Anticyclonic northerly \\
NZ & Cyclonic northerly \\
HNA & Icelandic high, ridge over Central Europe \\
HNZ & Icelandic high, trough over Central Europe \\
HB & High over the British Isles \\
TRM & Trough over Central Europe \\
NEA & Anticyclonic north-easterly \\
NEZ & Cyclonic north-easterly \\
HFA & Scandinavian high, ridge over Central Europe \\
HFZ & Scandinavian high, trough over Central Europe \\
HNFA & High Scandinavia-Iceland, ridge over Central Europe \\
HNFZ & High Scandinavia-Iceland, trough over Central Europe \\
SEA & Anticyclonic south-easterly \\
SEZ & Cyclonic south-easterly \\
SA & Anticyclonic southerly \\
SZ & Cyclonic southerly \\
TB & Low over the British Isles \\
TRW & Trough overn Europe \\
\hline &
\end{tabular}

2018. For this, a pair of principal component (PC) time series (RMM1 and RMM2) are computed based on the combined fields of near-equatorially averaged 850 -hPa zonal wind, 200$\mathrm{hPa}$ zonal wind and satellite-observed outgoing longwave radiation (OLR). There is no need for the additional removal of ENSO as the mean of the previous 120 days is subtracted from the RMM values (Lin et al. 2008; Gottschalck et al. 2010), and the MJO amplitude, $\sqrt{\mathrm{RMM}^{2}+\mathrm{RMM}^{2}}$, and phase are then computed from this. When MJO amplitude $\geq 1$, the MJO is considered active, and days when the MJO is weak or inactive, when $\mathrm{MJO}$ amplitude $<1$, are termed here as phase 0 . The MJO phases are classified categorically into eight phases, as in Wheeler and Hendon (2004). The MJO phases represent active convection over different regions: phases 2 and 3 over the Indian Ocean, phases 4 and 5 over the Maritime Continent, phases 6 and 7 over the Pacific Ocean, and phases 8 and 1 over the Atlantic and Africa. 
The NAE-CWR time series is derived using ERA-Interim reanalysis data (Dee et al. 2011), computed using a similar method performed in Cassou (2008). Daily 500-hPa geopotential height anomalies are computed relative to the mean 1979-2018 NDJFM seasonal cycle over the NAE region $\left(90^{\circ} \mathrm{W}-30^{\circ} \mathrm{E}, 20^{\circ}-80^{\circ} \mathrm{N}\right)$. The clustering is performed in the empirical-orthogonal-function phase space with 14 modes retained, corresponding to $85.8 \%$ of the variance. The $k$-means clustering algorithm is then applied to the anomalies to obtain the four NAE-CWRs, corresponding to the NAE large-scale circulation patterns.

Statistical evidence of the interaction between the MJO and the GWL are subjected to significance testing. There are two possible outcomes: either each GWL regime occurs after an MJO event or it does not. Thus, the number of occurrences of each GWL regime after MJO events follows a binomial distribution. By considering $29 \mathrm{GWL}$ regimes instead of four NAE-CWRs, the sample size is smaller and the hypothesised (climatological) probability of each GWL regime occurring is much lower. Following the central limit theorem, the normal approximation to the binomial distribution is not valid as the sample size is not sufficiently large in some cases; hence, the $z$-test cannot be used. Here, we perform the binomial test at the 95\% confidence level for significance testing of changes in frequency of each GWL regimes, and the $\chi^{2}$ test at the $99 \%$ confidence level for significance testing of changes in the combined 29 GWL regime distribution. Results are significant only if it passes both the binomial test and the $\chi^{2}$ test. We advise interpreting a slightly lower significance threshold in reality due to the persistence of the MJO events and GWL regimes, but have used this method for consistency and easy comparability with Cassou (2008).

\section{Matching the GWL with the NAE-CWRs}

Previous studies used, for example, 500-hPa geopotential height to explore the spatial anomalies for different weather regimes (Vautard 1990; Cheng and Wallace 1993; Michelangeli et al. 1995; Smyth et al. 1999; Yiou et al. 2008). Here, we match the 29 synoptic scale GWL regimes to the four large-scale NAE-CWRs. This allows for the identification and comparison of similarities in the spatial anomaly patterns, the teleconnection patterns (Section 4) and the transitions (Section 5). Table 2 shows this matching, computed by calculating the percentage of days in each NAE-CWR for each GWL regime. For each GWL, the NAE-CWR with the leading percentage match is used to determine the weather regime group (Table 2, rightmost column). The GWL regimes with higher percentage values in the group indicate higher similarity to the associated NAE-CWR. The GWL regime with the closest match to a single NAE-CWR is SWA with $90.3 \%$ of the days matching NAO+. Conversely, SEZ is the
Table 2 Matching the 29 GWL regimes to the four NAE-CWRs, shown as a percentage (rounded to 1 d.p.) of days (occurrences) in each NAE-CWR for each GWL regime, for all NDJFM seasons from 1979 to 2018. For each GWL, the NAE-CWR with the leading percentage match is used to determine the weather regime group, shown in italics and noted in the rightmost column

\begin{tabular}{llllll}
\hline GWL & NAO & NAO+ & AR & SB & Weather regime group \\
& - & & & & \\
\hline WA & $0.2 \%$ & $62.5 \%$ & $20.1 \%$ & $17.2 \%$ & NAO+ \\
WZ & $2.6 \%$ & $66.0 \%$ & $30.1 \%$ & $0.4 \%$ & NAO+ \\
WS & $52.4 \%$ & $18.8 \%$ & $28.3 \%$ & $0.5 \%$ & NAO- \\
WW & $1.6 \%$ & $68.1 \%$ & $20.5 \%$ & $9.7 \%$ & NAO+ \\
SWA & $1.8 \%$ & $90.3 \%$ & $4.5 \%$ & $3.3 \%$ & NAO+ \\
SWZ & $26.4 \%$ & $69.0 \%$ & $4.2 \%$ & $0.4 \%$ & NAO+ \\
NWA & $13.0 \%$ & $12.3 \%$ & $27.8 \%$ & $46.8 \%$ & SB \\
NWZ & $7.2 \%$ & $12.8 \%$ & $76.2 \%$ & $3.8 \%$ & AR \\
HM & $5.4 \%$ & $32.7 \%$ & $3.5 \%$ & $58.4 \%$ & SB \\
BM & $0.6 \%$ & $15.8 \%$ & $22.6 \%$ & $61.0 \%$ & SB \\
TM & $19.7 \%$ & $0.8 \%$ & $64.8 \%$ & $14.8 \%$ & AR \\
NA & $21.3 \%$ & $14.0 \%$ & $15.2 \%$ & $49.4 \%$ & SB \\
NZ & $39.8 \%$ & $0.9 \%$ & $51.1 \%$ & $8.1 \%$ & AR \\
HNA & $71.2 \%$ & $1.3 \%$ & $4.5 \%$ & $23.1 \%$ & NAO- \\
HNZ & $86.3 \%$ & $0.7 \%$ & $8.2 \%$ & $4.8 \%$ & NAO- \\
HB & $10.2 \%$ & $0.0 \%$ & $14.8 \%$ & $75.0 \%$ & SB \\
TRM & $11.2 \%$ & $12.8 \%$ & $62.6 \%$ & $13.4 \%$ & AR \\
NEA & $10.1 \%$ & $2.0 \%$ & $4.0 \%$ & $83.8 \%$ & SB \\
NEZ & $1.8 \%$ & $7.6 \%$ & $22.9 \%$ & $67.6 \%$ & SB \\
HFA & $1.5 \%$ & $10.8 \%$ & $1.5 \%$ & $86.2 \%$ & SB \\
HFZ & $15.5 \%$ & $14.0 \%$ & $9.3 \%$ & $61.2 \%$ & SB \\
HNFA & $44.6 \%$ & $1.0 \%$ & $0.0 \%$ & $54.5 \%$ & SB \\
HNFZ & $66.9 \%$ & $0.0 \%$ & $10.2 \%$ & $22.9 \%$ & NAO- \\
SEA & $11.0 \%$ & $25.4 \%$ & $3.4 \%$ & $60.2 \%$ & SB \\
SEZ & $28.6 \%$ & $31.3 \%$ & $22.3 \%$ & $17.9 \%$ & NAO+ \\
SA & $12.7 \%$ & $60.3 \%$ & $5.0 \%$ & $22.0 \%$ & NAO+ \\
SZ & $59.0 \%$ & $34.3 \%$ & $4.8 \%$ & $1.8 \%$ & NAO- \\
TB & $73.0 \%$ & $6.6 \%$ & $20.4 \%$ & $0.0 \%$ & NAO- \\
TRW & $19.7 \%$ & $15.7 \%$ & $60.5 \%$ & $4.1 \%$ & AR \\
\hline & & & & & \\
\hline
\end{tabular}

GWL regime which least distinctly maps to any of the four NAE-CWRs, matching $31.3 \%$ to NAO+ but then with an almost indistinguishable difference of $28.6 \%$ to NAO.

The GWL regimes are next ranked by their percentage match to their weather regime group (leading NAE-CWR), in descending order from closest to furthest match, shown in Table 3.

Next, we present the climatologies of the $500-\mathrm{hPa}$ geopotential height anomalies for the GWL regimes (spatial anomaly patterns). These are grouped by the NAE-CWRs (Table 3), to show the similarities between each NAE-CWR and the associated GWL regimes in capturing both the largescale and synoptic scale flow characteristics. 
Table 3 Weather regime groups and their rankings of the $29 \mathrm{GWL}$ regimes. GWL regimes are listed in order according to the similarity to the associated NAE-CWR based on percentage values from Table 2. A higher percentage value indicates higher similarity to the associated NAE-CWR

\begin{tabular}{llcc}
\hline NAO- & NAO+ & Atlantic ridge (AR) & Scandinavian blocking (SB) \\
\hline HNZ, TB, HNA, HNFZ, SZ, WS & SWA, SWZ, WW, WZ, WA, SA, SEZ & NWZ, TM, TRM, TRW, NZ & $\begin{array}{c}\text { HFA, NEA, HB, NEZ, HFZ, BM, } \\
\text { SEA, HM, HNFA, NA, NWA }\end{array}$ \\
\hline
\end{tabular}

For the NAO- NAE-CWR, the positive anomalies occur mainly over Greenland and Iceland (Fig. 1), while the negative anomalies occur over the mid-North Atlantic and extend over Northwest Europe. This $k$-means cluster-derived NAECWR anomaly pattern is mostly consistent with the definition of the NAO- weather regime using both the principal component-based NAO index and the Hurrell NAO index (station-based; Hurrell 1995). Differences are due to the properties of the $k$-means-derived NAO- not being an exact opposite of its NAO+ NAE-CWR, nor does it have any orthogonality with AR or SB NAE-CWRs. The anomaly patterns for HNZ and TB are very similar to the NAO- NAE-CWR, although the magnitude and location of peak anomalies differ marginally. The anomaly patterns for TB is associated with a northwest-southeast alignment compared with the north-south alignment for the NAO- NAE-CWR, while the positive anomalies are stronger in HNZ compared with the NAONAE-CWR. The anomaly pattern for HNA resembles HNZ, except that the positive anomalies extend over Central Europe, associated with a ridge. These localised differences between the anomaly patterns are captured by the GWL but not the NAE-CWR. Other localised differences are also reflected in the anomaly patterns for HNFZ, SZ and WS.

In contrast to the NAO- NAE-CWR, the signs of the anomalies are reversed for the NAO+ NAE-CWR (Fig. 2). This NAE-CWR anomaly pattern is also mostly consistent
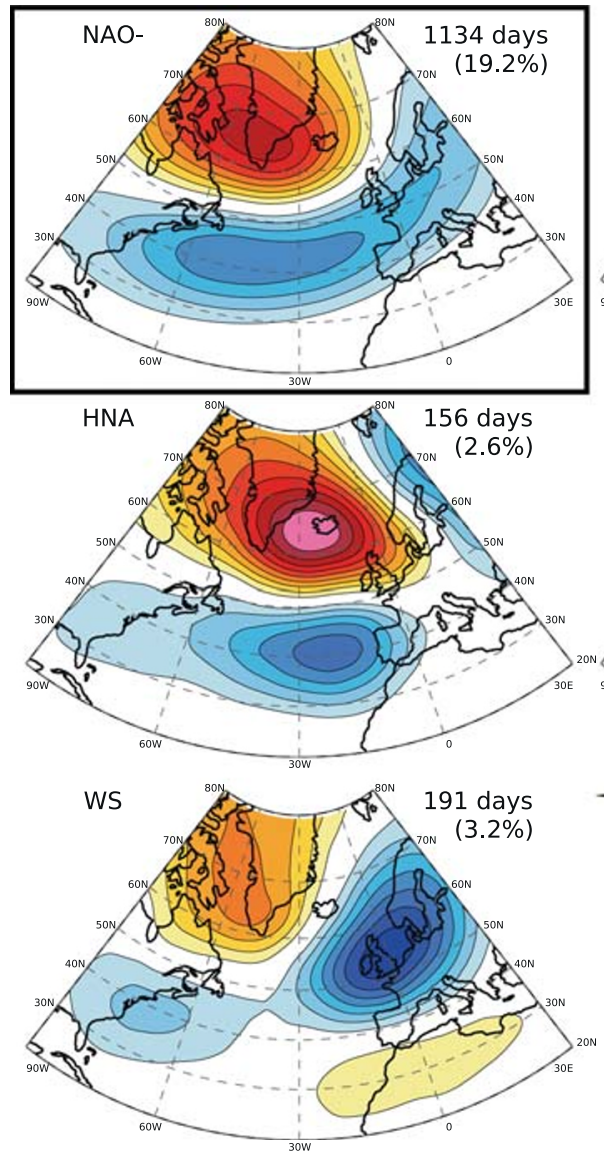

Fig. 1 Composite daily 500-hPa geopotential height anomaly climatology for the NAO- weather regime group. The mean anomalies are relative to the mean 1979-2018 NDJFM seasonal cycle. The GWL regimes are listed in order from left to right, top to bottom according to the similarity
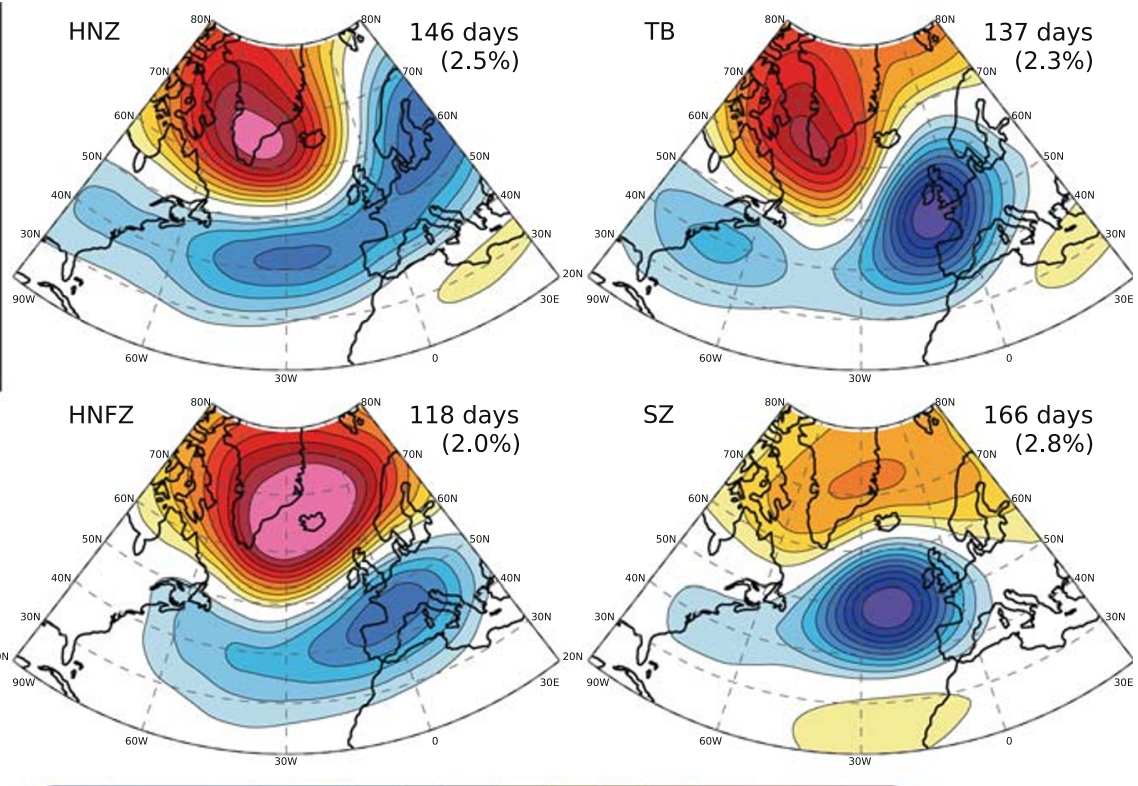

$\begin{array}{llllllllllllllllll}-225 & -200 & -175 & -150 & -125 & -100 & -75 & -50 & -25 & 25 & 50 & 75 & 100 & 125 & 150 & 175 & 200 & 225\end{array}$

to the NAO- NAE-CWR. The percentage and number of days represent the frequencies of the NAO- NAE-CWR and GWL regimes in their corresponding time series. Contour intervals are $25 \mathrm{~m}$ 

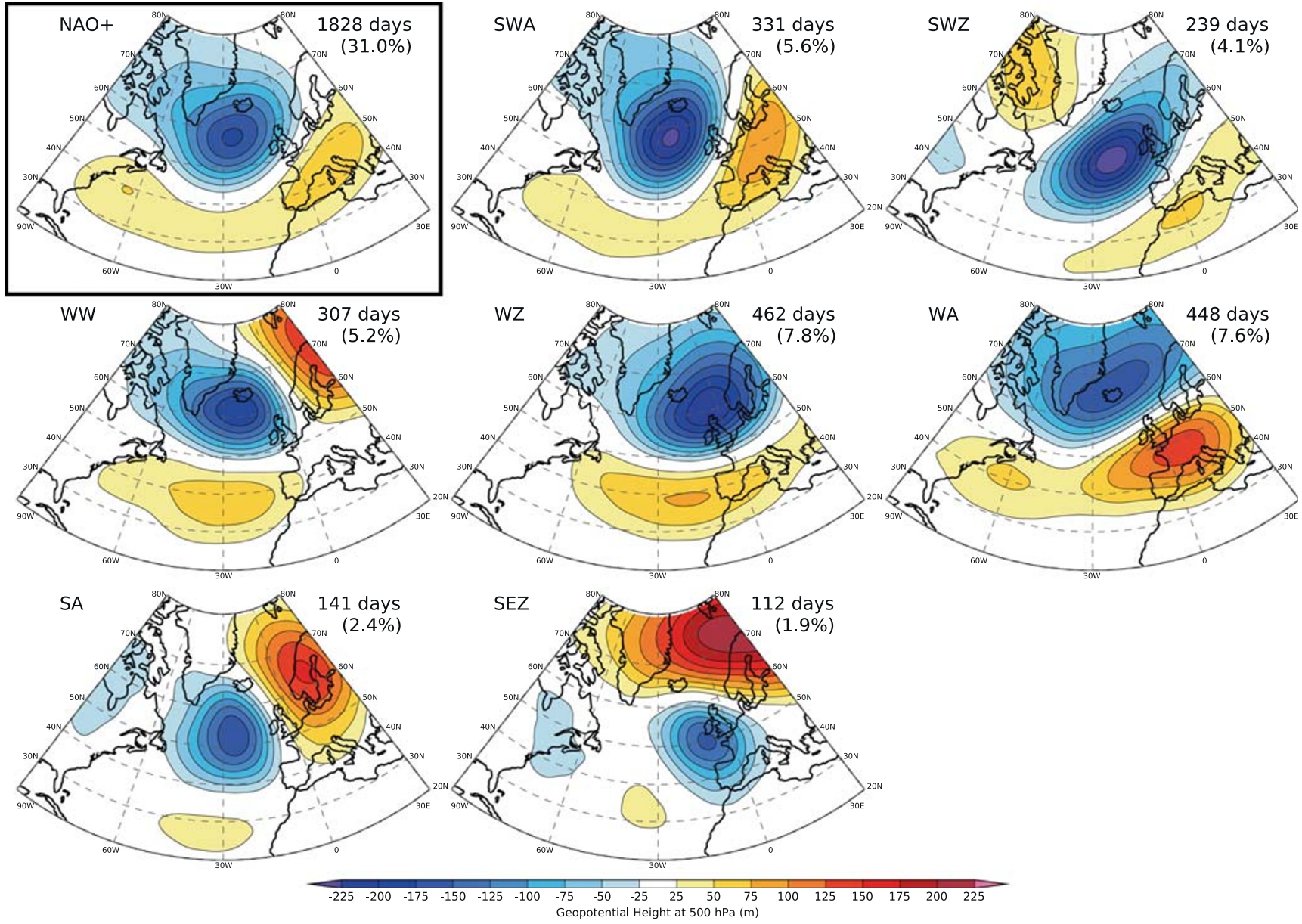

Fig. 2 As in Fig. 1, but for the NAO+ weather regime group

with the definition of the NAO+ NAE-CWR using both the principal component-based NAO index and the Hurrell NAO index. The anomaly patterns for SWA, WZ and WA are very similar to the NAO+ NAE-CWR, although there exist minor differences. Most notably, the positive anomalies are larger than the negative anomalies in WA. The opposite occurs for WZ. The anomaly pattern for WA matches the NAO+ NAECWR more closely; both have anomaly patterns associated with a northwest-southeast alignment. The negative anomalies for WZ are shifted slightly east, yielding a north-south alignment. There are negative anomalies extending over Central Europe in the anomaly pattern for WW, reminiscent of the anomaly pattern for HNA contrasted. The spatial anomaly patterns suggest that transition stages between the NAECWRs are captured by certain GWL regimes. Although SWZ is statistically mapped by leading percentage match to the NAO+ NAE-CWR, the anomaly pattern for SWZ appears partway between the NAO- and NAO+ NAE-CWRs. The positive anomalies over Greenland and weak negative anomalies over Scandinavia are characteristic of the NAO- NAECWR while the strong negative anomalies over the North Atlantic are characteristic of the NAO+ NAE-CWR. This is a possible indicator that SWZ occurs as NAO- and NAO+ NAE-CWRs transition between each other.

For the AR NAE-CWR, the positive anomalies occur over the North Atlantic and negative anomalies occur over the Scandinavian region extending into Central Europe (Fig. 3). The anomaly patterns for NWZ and TRM are very similar; the magnitude of the positive anomalies over the North Atlantic is comparable for NWZ, TRM and the AR NAE-CWR, although the negative anomalies over Scandinavia are stronger for NWZ. Comparatively, there is a slightly northward shift in the anomaly patterns for TM and NZ, particularly the positive anomalies. The anomalies are also substantially stronger in $\mathrm{TM}$ and NZ. Interestingly, the positive anomalies for TM and NZ extend over Iceland and Greenland, which is characteristic of the anomaly pattern for the NAO-NAE-CWR. This is consistent with the mapping of GWL regimes to NAECWRs; TM and NZ are second most similar to the NAONAE-CWR by leading percentage match.

For the SB NAE-CWR, the positive anomalies occur over the Scandinavian region, British Isles and Iceland (Fig. 4) while weak negative anomalies occur over the Labrador Sea. There exists substantial variation in the anomaly patterns for 


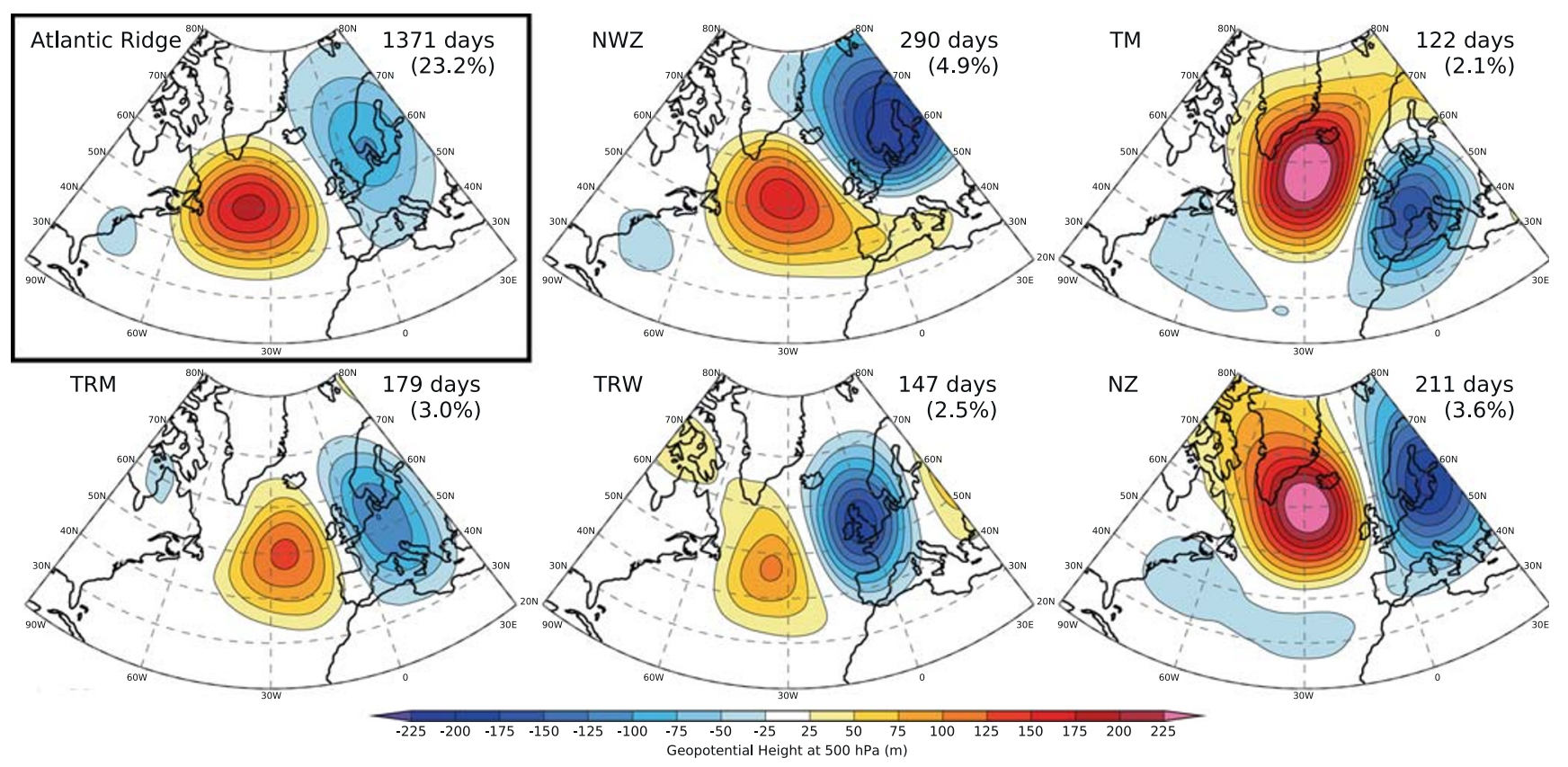

Fig. 3 As in Fig. 1, but for the AR weather regime group

the GWL regimes in the SB weather regime group, capturing localised differences which are absent in the NAECWR. Only the anomaly patterns for HFA, SEA and $\mathrm{HM}$ are somewhat similar to the SB NAE-CWR; the negative-positive anomaly patterns aligned west-east. Of the eleven anomaly patterns for the GWL regimes in the SB weather regime group, some are distinctly different from the SB NAE-CWR. In particular, the anomaly pattern for HNFA stands out because of the associated northsouth alignment instead of west-east. Like SWZ, HNFA also captures the transition stages between two NAECWRs, with the anomaly pattern for HNFA appearing to follow a pattern between the SB and NAO- NAE-CWRs. There are strong positive anomalies over Greenland and Iceland, along with negative anomalies over the Atlantic. This is characteristic of the NAO- NAE-CWR, except that the strong positive anomalies over Greenland extend eastwards over Scandinavia, so it matches SB NAE-CWR more closely (54.5\% leading percentage match compared with $44.6 \%$ ). This indicates that HNFA may be capturing the natural evolution of large-scale circulation patterns from the SB NAE-CWR to the NAO- NAE-CWR, following the westward retrogression of the Scandinavian block over Greenland and Iceland described in Vautard (1990). This example highlights how well the GWL account for the localised anomaly patterns around the Scandinavian block compared with the NAE-CWR (yielding eleven GWL regimes instead of one). This is extremely advantageous in diagnosing the different types of Scandinavian block which may be influenced differently by the MJO.

\section{MJO influence on occurrences of weather regimes}

Next, we follow the methodology of Cassou (2008) to reproduce and update the MJO to NAE-CWR contingency tables to show the percentage change in anomalous frequency of occurrence at 0-20 days lagged from the MJO, highlighting the impact of the teleconnections. These additionally include the MJO to GWL contingency tables, all grouped by the NAECWRs. As noted in Cassou (2008), the presence of a slope as a function of lag and significant results over multiple lag days as the MJO progresses is indicative of an MJO forcing. We refer to the patterns in the contingency tables as teleconnection patterns. The dynamical mechanisms behind them have been described in Cassou (2008) and Lee et al. (2019).

The MJO teleconnection pattern analysis for the NAOweather regime group is shown in Fig. 5. The statistical evidence presented here is consistent with Cassou (2008) in suggesting that MJO phase 6 can be interpreted as a precursor of the NAO- NAE-CWR. Following the mapping to the NAONAE-CWR, MJO teleconnection patterns for associated GWL regimes in the group are also assessed. Figure 5 shows that 10-15 days after MJO phase 7, the frequencies of HNZ and TB are both increased by $\sim 75 \%$. By contrast, they are reduced by $\sim 60 \%$ and $\sim 80 \%$ respectively $10-15$ days after MJO phase 3. These are significant over multiple lag days with a slope as a function of lag. The shift in significant changes in regime frequency as the MJO progresses is also in accordance with the typical persistence of each MJO phase, as in Cassou (2008). The MJO teleconnection patterns for these GWL regimes are very similar to the NAO- NAE- 

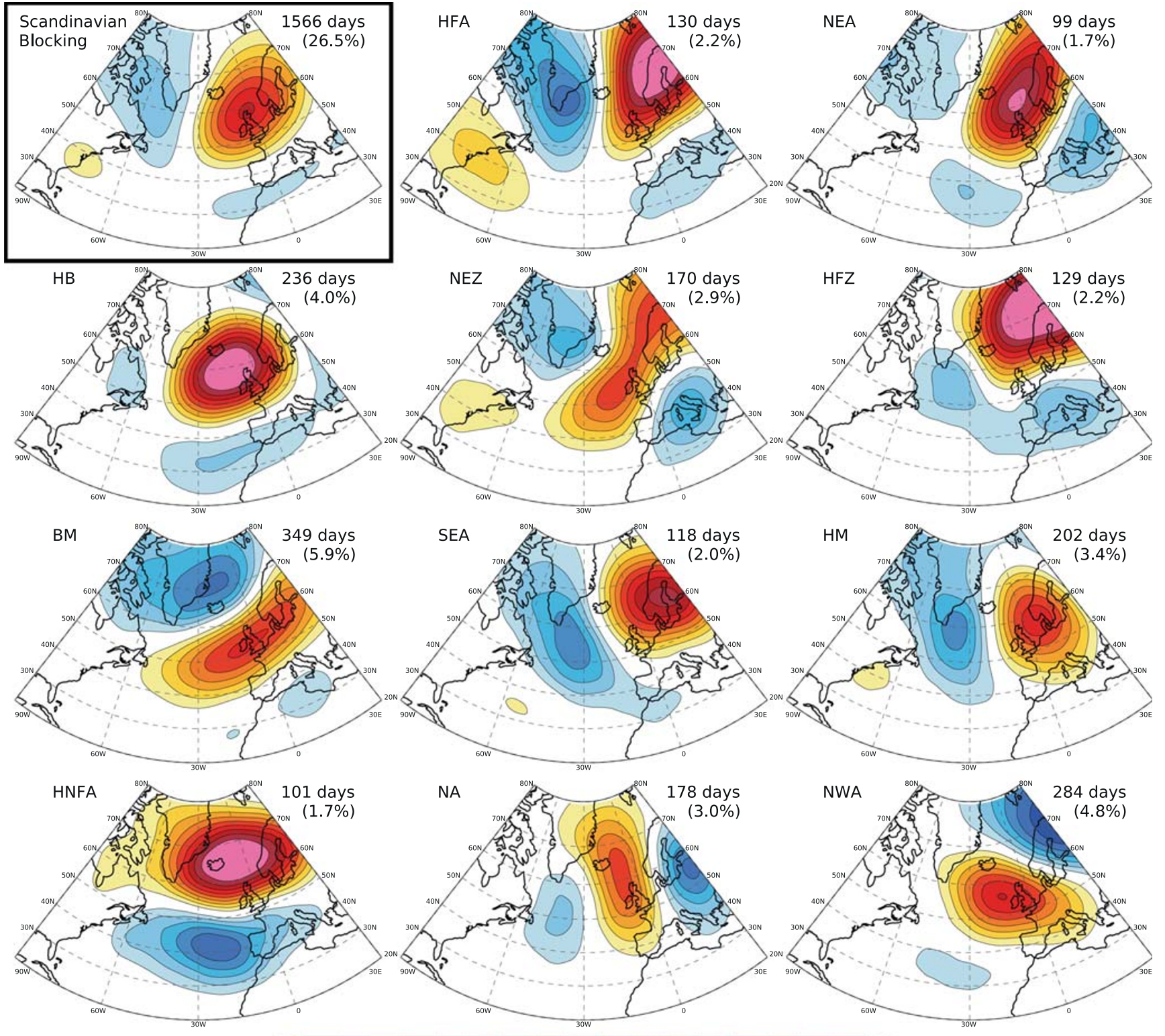

$\begin{array}{lllllllllllr}-225 & -200 & -175 & -150 & -125 & -100 & -75 & -50 & -25 & 25 & 50 & 75 \\ & & & & & & & \end{array}$

Fig. 4 As in Fig. 1, but for the SB weather regime group

CWR, although the magnitude of their changes in frequencies is generally larger. This result is unsurprising since the spatial anomaly patterns for HNZ and TB are very similar to the NAO- NAE-CWR (Fig. 1).

Even though HNA, HNFZ, SZ and WS are mapped to the NAO- NAE-CWR, the expected MJO teleconnection pattern is not observed. The frequencies of these GWL regimes do not change significantly following the typical progression of the MJO. While there are marginal changes to the frequency of HNA for MJO phases 1, 2 and 8, these results are not significant over multiple lag days and so may be considered statistical noise. This absence of significance for HNA suggests that the presence of the ridge over Central Europe (Fig. 1) plays a dominant role in inhibiting the MJO influence. To test that this observation is not altered by instances where HNZ, TB and HNA are more similar to the other NAE-CWRs instead of NAO-, their spatial anomaly patterns are composited over days when the NAE large-scale circulation patterns also correspond to the NAO- NAE-CWR $(86.3 \%, 73.0 \%$ and $71.2 \%$ of each GWL regime's total occurrences respectively; Fig. 6).

Next, we repeat the MJO teleconnection pattern analysis for the NAO+ weather regime group (Fig. 7). In contrast to the NAO- NAE-CWR, MJO phase 3 can be interpreted as a precursor of the NAO+ NAE-CWR, consistent with Cassou (2008). As before, the MJO teleconnection patterns for the associated GWL regimes in the group are assessed. Figure 7 shows that 10-15 days after MJO phase 3, the frequencies of SWA, WZ and WA are increased by $\sim 50 \%, \sim 50 \%$ and $\sim 75 \%$ 


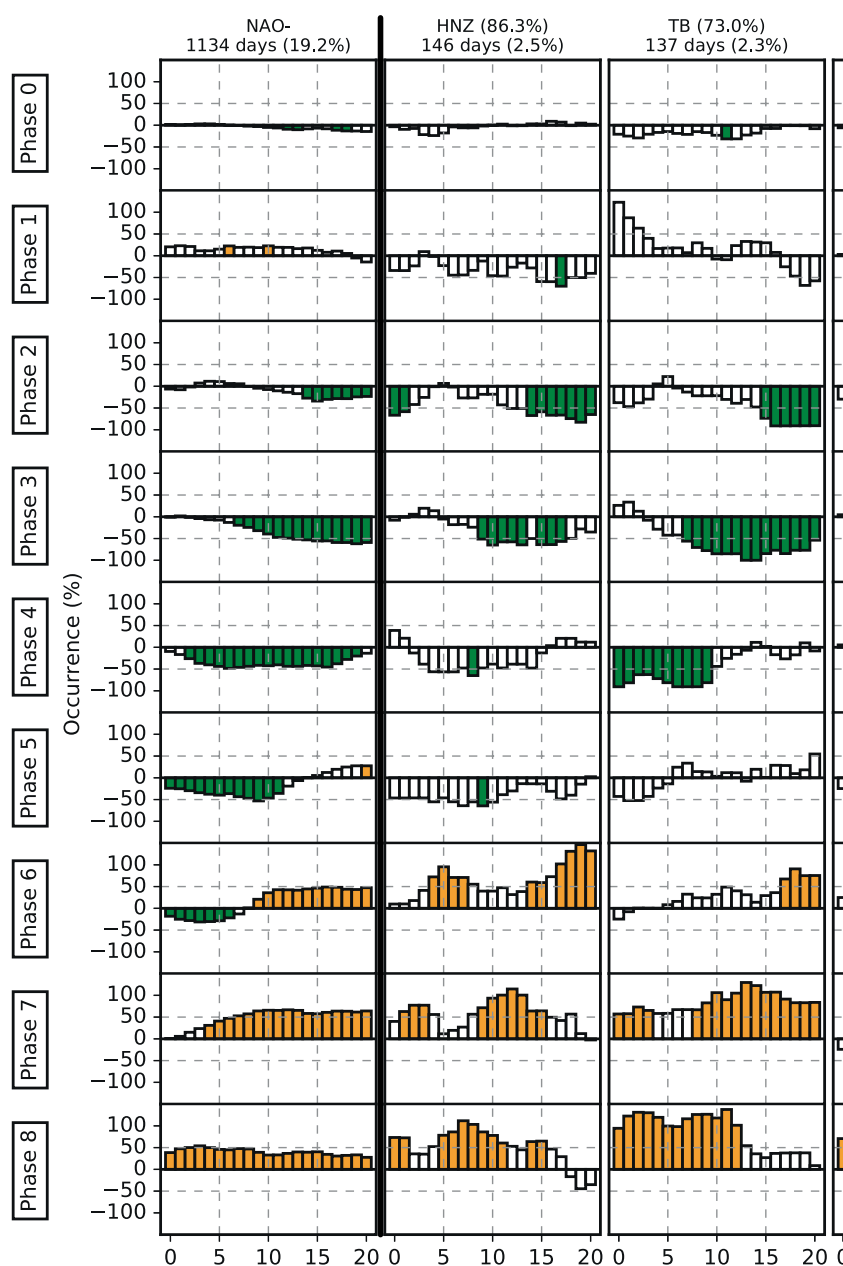

Fig. 5 Contingency table between the MJO phases (rows) and the NAOweather regime group consisting of the NAO- NAE-CWR and the six associated and ranked GWL regimes (columns). The bars represent the anomalous percentage occurrence from climatology as a function of lag days (GWL regimes lagging MJO phases). An anomaly of $0 \%$ indicates that the probability of occurrence of a regime is equal to climatology. An anomaly of $100 \%$ indicates that the probability of occurrence is $100 \%$ more likely (doubled) compared with climatology. An anomaly of $100 \%$ indicates no occurrence of the regime. The green and orange bars

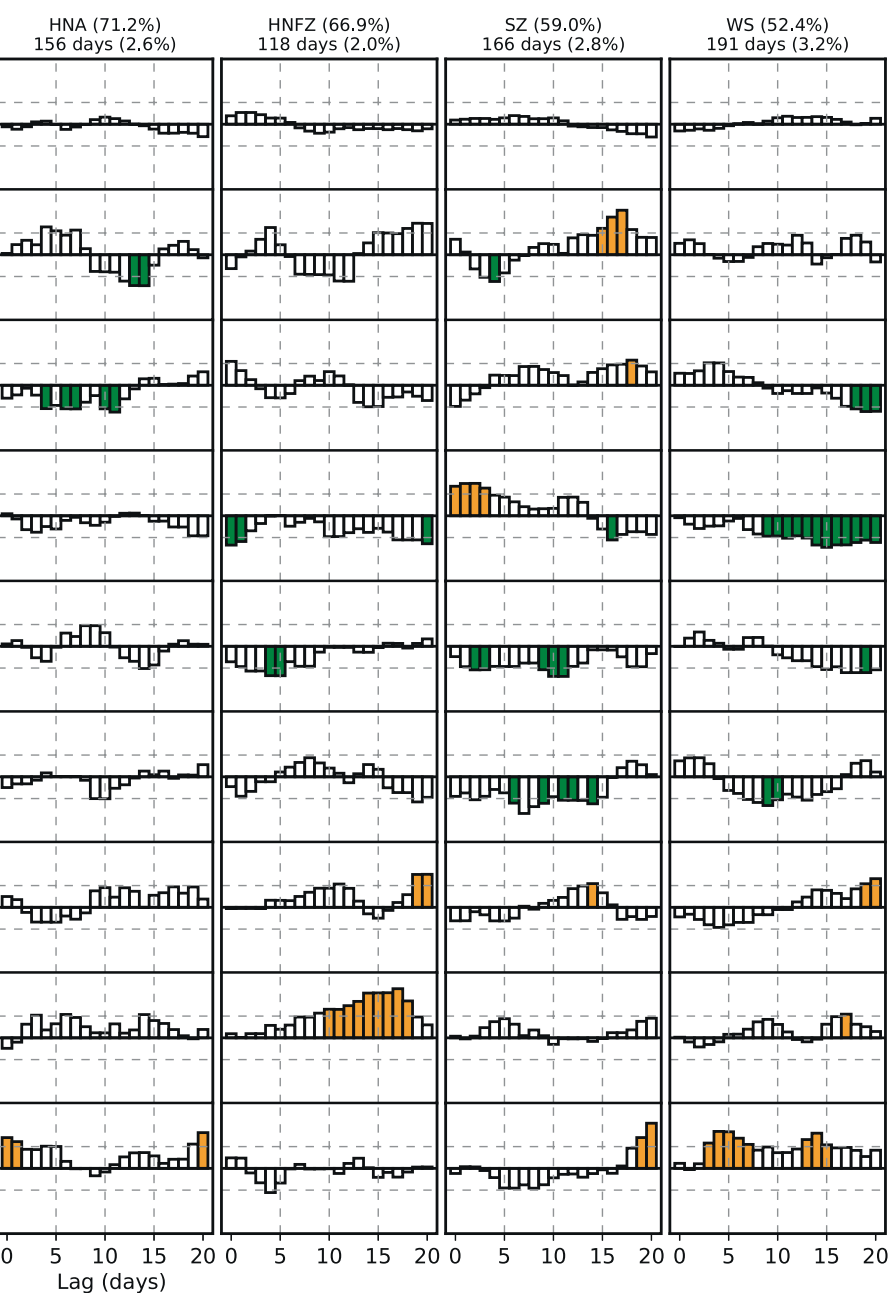

indicate that the result is statistically significant: both significant at the $99 \%$ confidence level using $\chi^{2}$ statistics and significant at the $95 \%$ confidence level using binomial statistics. The percentage and number of days below the GWL regime represent the frequency of the GWL regime for all 39 NDJFM seasons from 1979 to 2018 . The percentage similarity beside the GWL regime label is taken from Table 2, and the GWL regimes (columns) are ranked by the percentage similarity, descending from left to right within the group
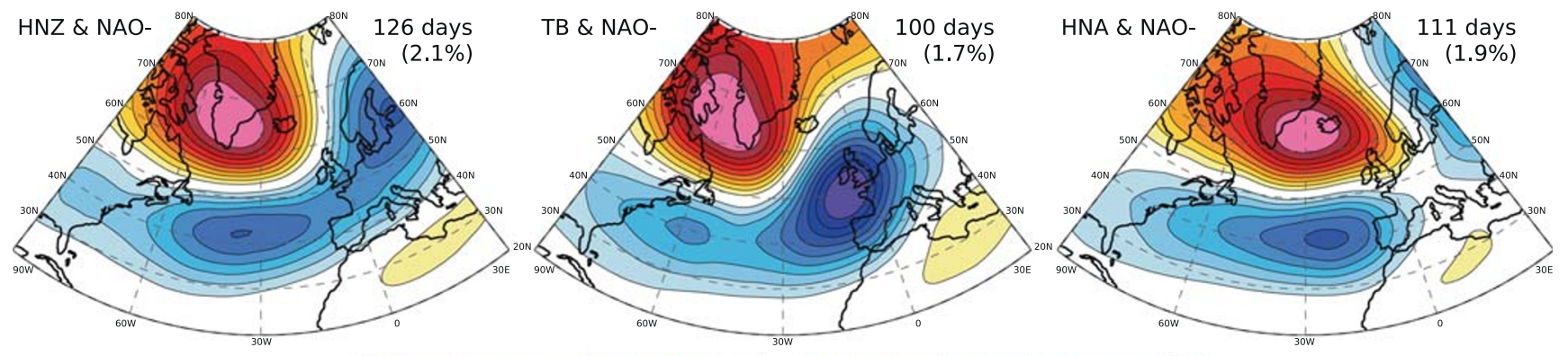

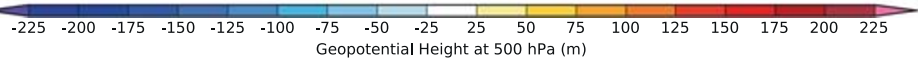

Fig. 6 Daily 500-hPa geopotential height anomalies for the HNZ, TB and HNA GWLs composited only for days when the NAE large-scale circulation patterns also correspond to NAO- NAE-CWR. The composited anomalies are relative to the full mean 1979-2018 NDJFM seasonal cycle. The percentage and number of days represent the frequencies of the GWL regimes in GWL time series. Contour intervals are $25 \mathrm{~m}$ 


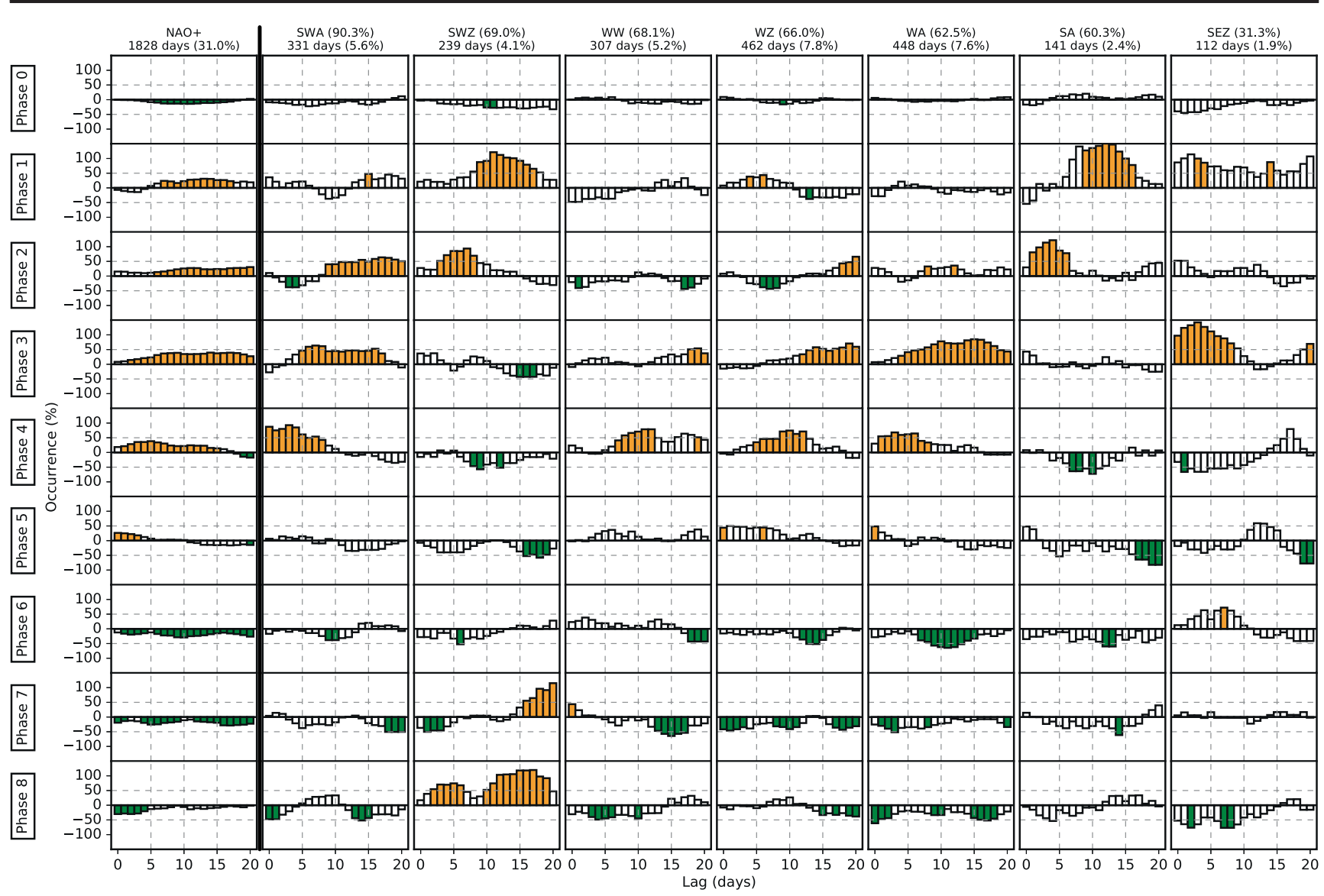

Fig. 7 As in Fig. 5, but for the NAO+ weather regime group consisting of the NAO+ NAE-CWR and the seven associated and ranked GWL regimes

respectively. Additionally, 10-15 days after phase 2, the frequency of SWA is increased by $\sim 50 \%$. Similar to the NAOweather regime group, these significant changes in regime frequency are indicative of an MJO forcing. Additionally, the MJO teleconnection patterns for these GWL regimes are very similar to the NAO+ NAE-CWR; this is unsurprising given the very similar spatial anomaly patterns for SWA, WZ, WA and NAO+ NAE-CWR (Fig. 2).

For the NAO+ weather regime group, the expected MJO phase 3 teleconnection pattern is not observed for SWZ, WW, SA and SEZ. The significantly increased frequencies are either confined to different MJO phases or weak following phases 2 and 3. This highlights the GWL regimes contributing to the MJO teleconnection patterns for the NAO+ NAECWR, again possibly associated with localised differences between the anomaly patterns. SWZ and SA contribute to the significant increased frequencies for MJO phases 1 and 2, SWA and WZ contribute for phases 2, 3 and 4, while WA contributes for phases 3 and 4 . Interestingly, there is an absence of significant results for WW, possibly due to the absence of a strong ridge over Central Europe. This is illustrated by comparing the spatial anomaly patterns for SWA, WZ, WA and WW composited over days when the NAE large-scale circulation patterns also correspond to the NAO+ NAE-
CWR $(90.3 \%, 66.0 \%, 62.5 \%$ and $68.1 \%$ of each GWL regime's total occurrences respectively; Fig. 8). Another interesting result is the presence of significant increased frequency for SWZ for phases 7 and 8, characteristic of the MJO teleconnection pattern for the NAO- NAE-CWR. This is supportive of the analysis of the anomaly patterns for SWZ (Fig. 2 ); it most often occurs as NAO- and NAO+ NAE-CWR transition between each other. Furthermore, the comparison of the spatial anomaly patterns for SWZ composited over days when the NAE large-scale circulation patterns also correspond to the NAO- or NAO+ NAE-CWRs (26.4\% and $69.0 \%$ of total SWZ occurrences respectively) highlights that SWZ may often resemble the NAO-NAE-CWR (Fig. 9), resulting in the MJO teleconnection pattern being seen between the two main $\mathrm{NAO}-$ and $\mathrm{NAO}+$ teleconnections. Therefore, following the phase progression of the MJO, it is possible that $\mathrm{SWZ}$ is more likely to occur prior to other GWL regimes in the NAO+ weather regime group.

Aside from the prominent MJO teleconnection patterns for the $\mathrm{NAO}-$ and $\mathrm{NAO}+$ weather regime groups, there are also observable patterns in the AR weather regime group. The AR NAE-CWR shows a small increase in frequency after MJO phase 4, and reduction in frequency after MJO phases 1, 2, 3, 7 and 8 (Fig. 10). However, it is only the reduction in 

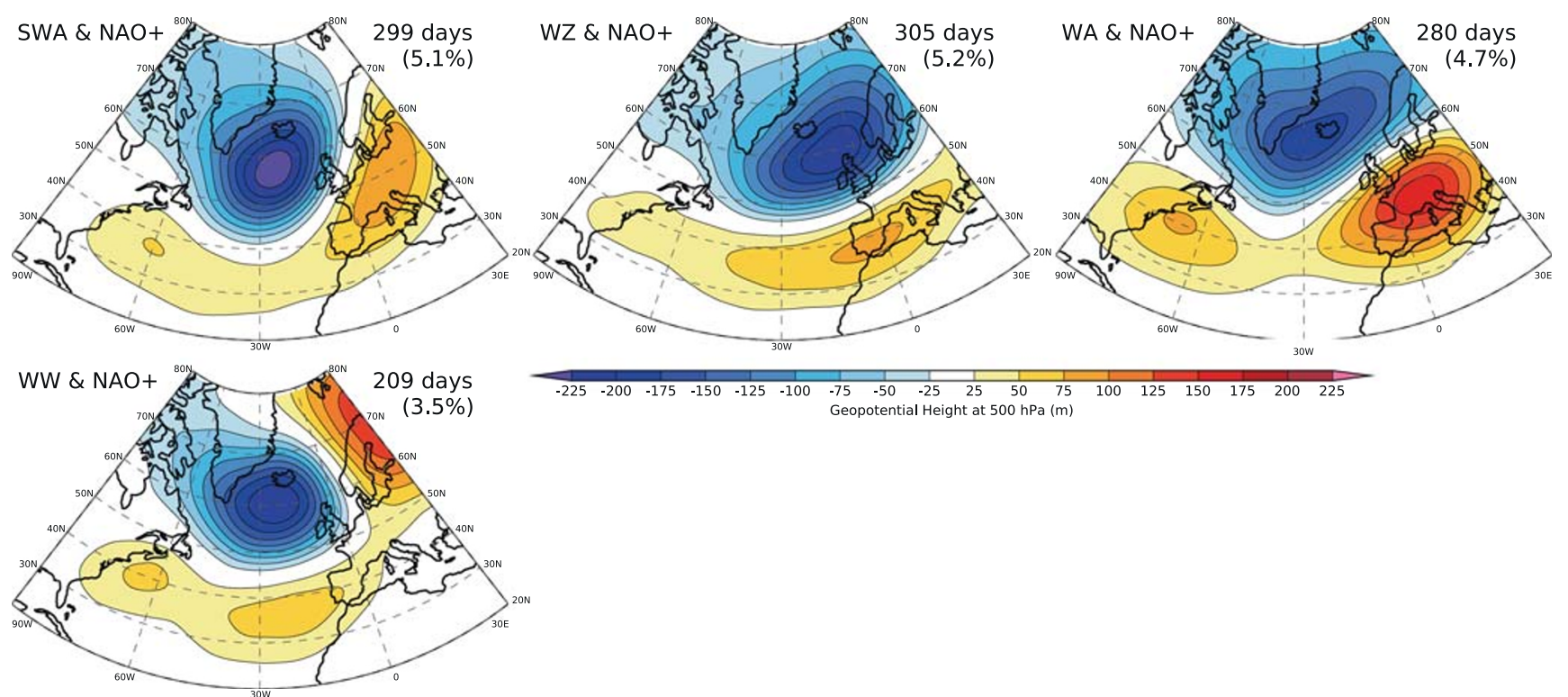

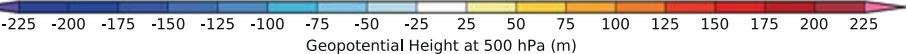

Fig. 8 As in Fig. 6, but for SWA, WZ, WA and WW composited only for days when the NAE large-scale circulation patterns also correspond to NAO+ NAE-CWR

frequency after MJO phases 1, 2 and 3 which consistently shift towards day 0 over successive phases. Cassou (2008) hypothesised that any reduction in frequency is related to the dominance of the NAO- or NAO+ NAE-CWRs during those phases by construction. TM and NZ mainly contribute to this reduction in frequency for MJO phases 1,2 and 3. There is an observable increase in frequencies for these same two GWL regimes as the $\mathrm{MJO}$ progresses from phases 5 to 8 , but without
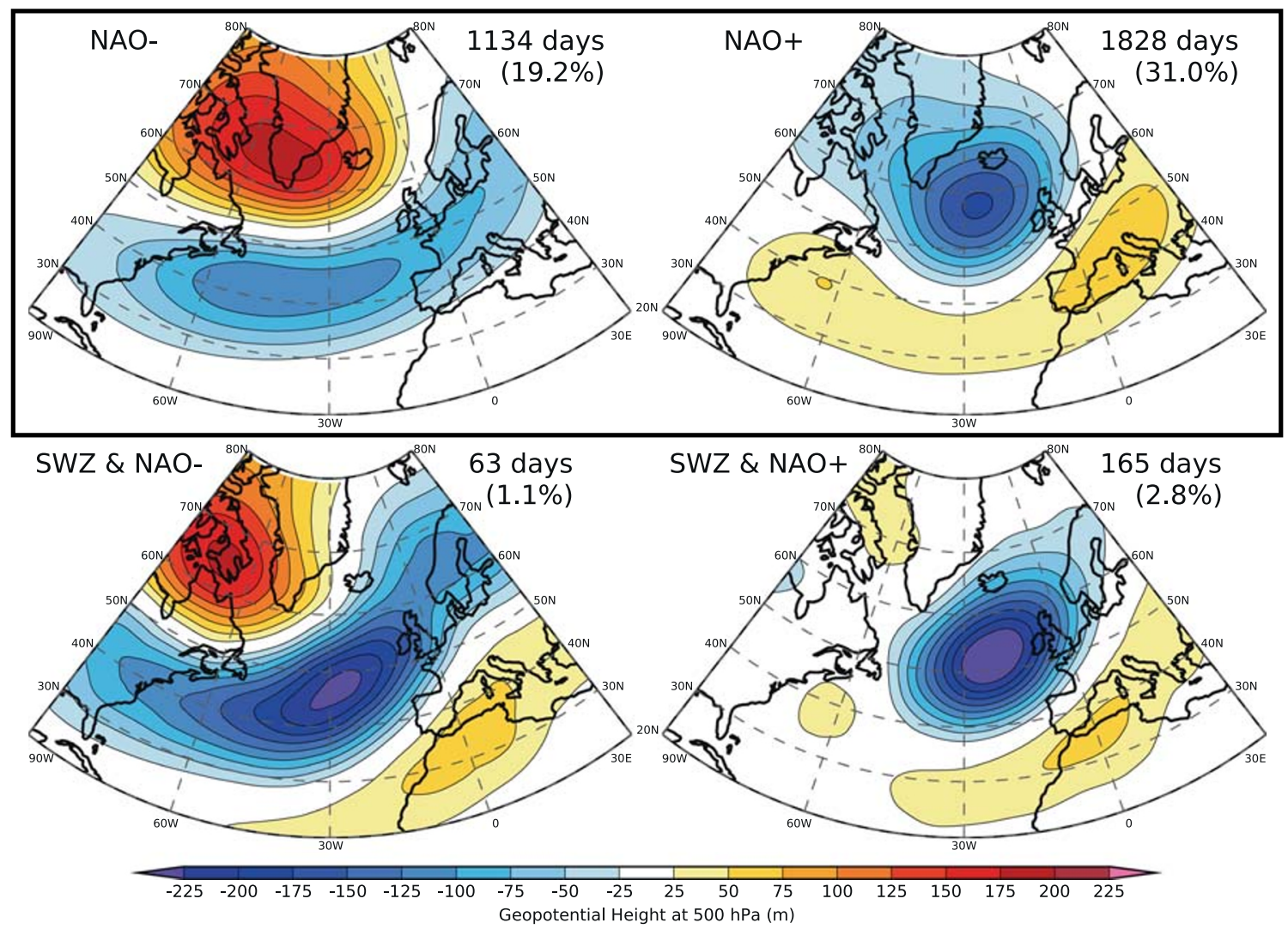

Fig. 9 As in Fig. 6, but for SWZ composited only for days when the NAE large-scale circulation patterns also correspond to NAO- NAE-CWR (bottom left) and NAO+ NAE-CWR (bottom right) respectively. The

spatial anomaly patterns for NAO- and NAO+ NAE-CWRs are replicated above from Figs. 1 and 2, for comparison 


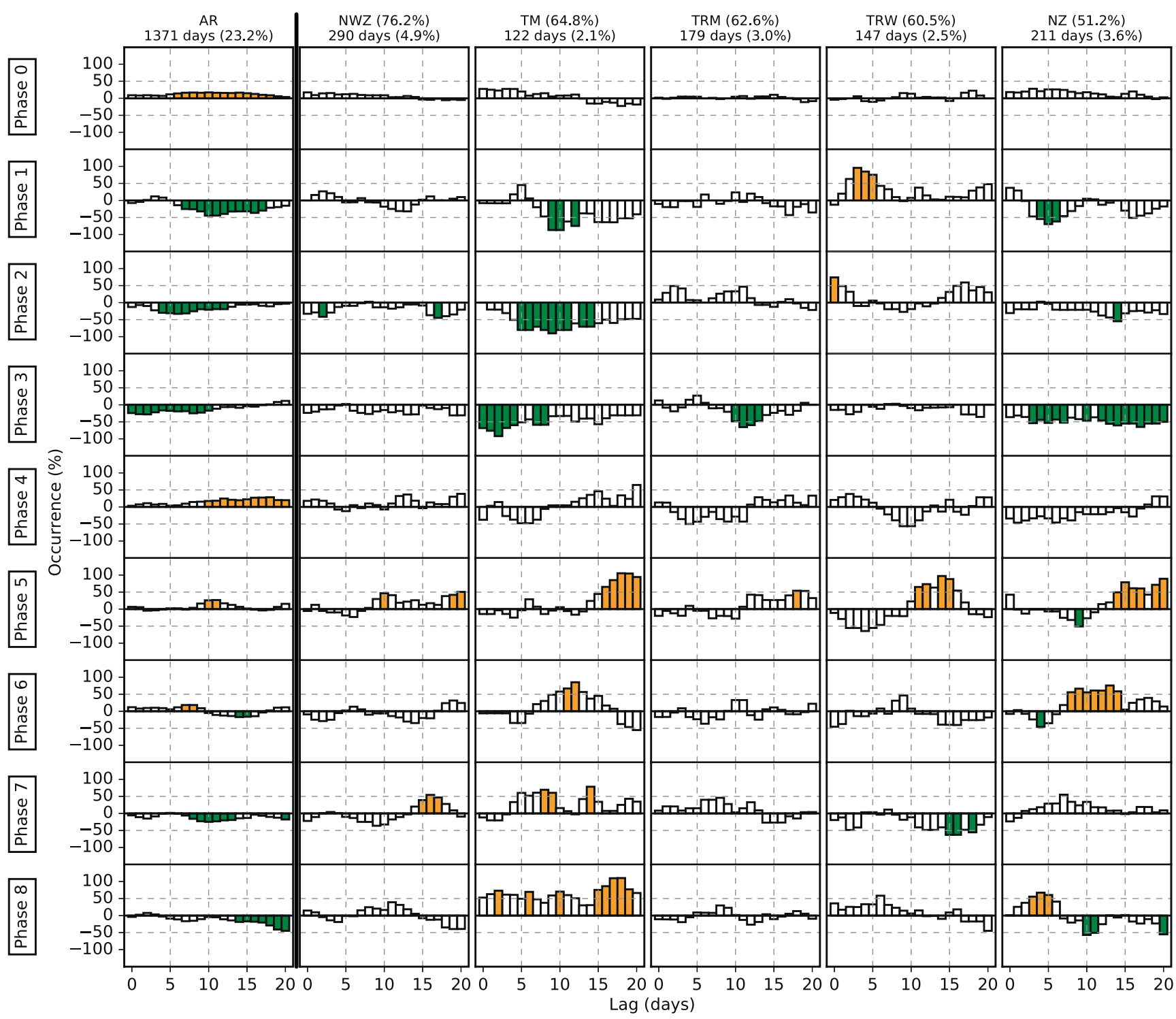

Fig. 10 As in Fig. 5, but for the AR weather regime group consisting of the AR NAE-CWR and the five associated and ranked GWL regimes

much significance. These characteristics are similar to the MJO teleconnection pattern for the NAO- NAE-CWR. The result is unsurprising following the analysis of the anomaly patterns for TM and NZ (Fig. 3). While NWZ and TRM are most similar to the AR NAE-CWR, they are not significantly affected by the dominance of both the NAO- and NAO+ NAE-CWRs. Together, this suggests there is no distinct AR teleconnection from the MJO even on the synoptic scales.

The MJO teleconnection pattern for the SB NAE-CWR is characterised by the increased frequency at a short lag time after MJO phases 5,6 and 7. This may be due to the enhanced excitation of NAO+ NAE-CWR during preceding MJO phases considering preferred transitions from $\mathrm{NAO}+$ to $\mathrm{SB}$ (Cassou 2008), also termed in situ development. This characteristic is only present in HFA, HB and NEZ, but the increased frequencies are not significant over multiple lag days (Fig. 11). It is likely that these could become significant given a larger dataset. There are also notable patterns for SEA and HNFA. There is a significant increase in the frequency of SEA for phase 2 over lag $0-16$ days. These increased anomalies are only confined to phase 2 ; this is explored later. There is also an increased frequency of HNFA by $\sim 120 \%$ for phase 5 at lag 9 13 days. The shift in the increased frequency with lag days as the MJO progresses from phases 5 to 7 suggests that this could be due to an MJO forcing, characteristic of the typical teleconnection pattern for the NAO- NAE-CWR but shifted one MJO phase earlier. This also supports the analysis of the anomaly patterns for HNFA (Fig. 4); it occurs as the SB NAECWR transitions to the NAO- NAE-CWR. Furthermore, the comparison of the spatial anomaly patterns for HNFA composited over days when the NAE large-scale circulation patterns also correspond to the SB or NAO- NAE-CWRs highlights that HNFA often strongly resemble the NAONAE-CWR, especially during the westward retrogression of 


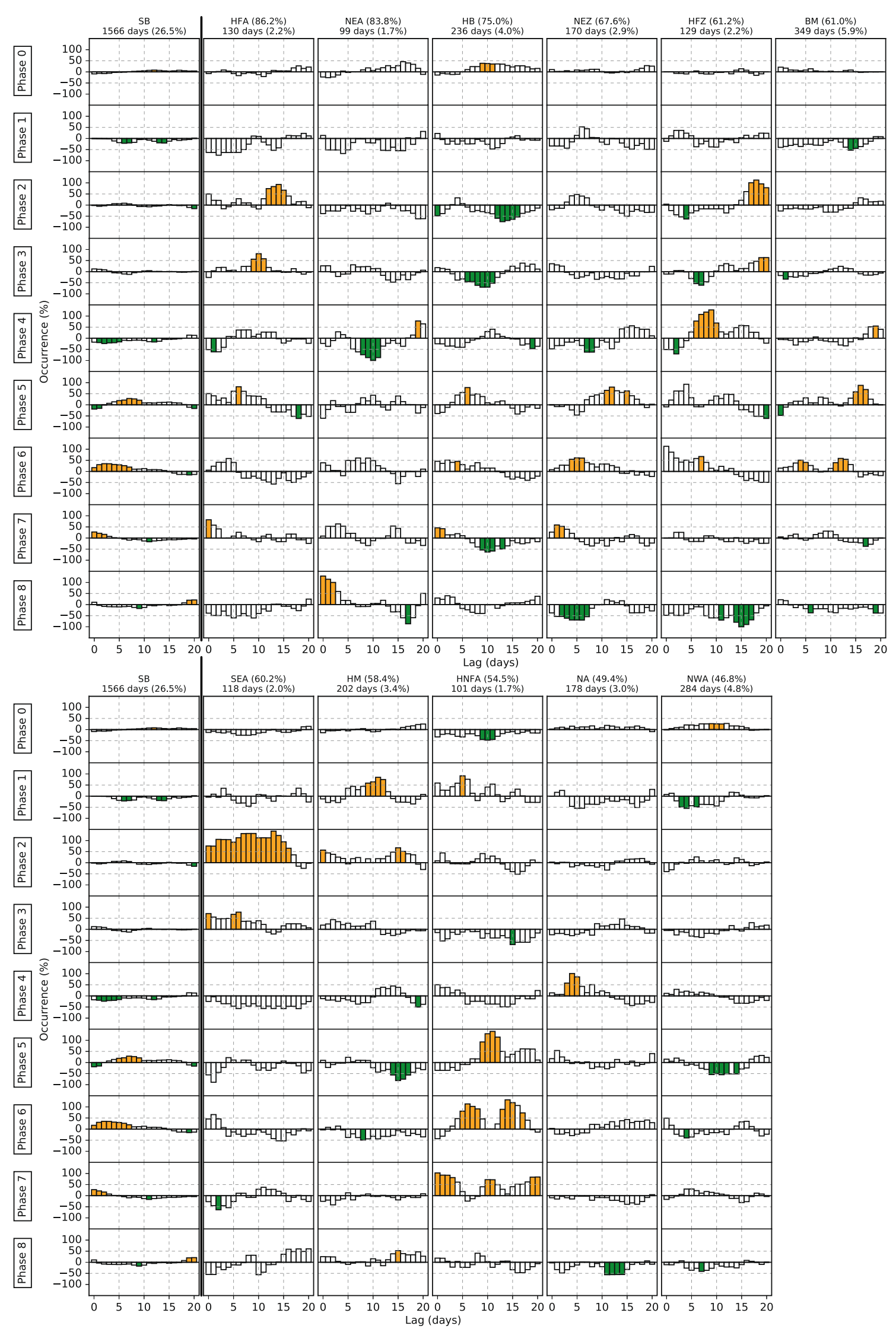

Fig. 11 As in Fig. 5, but for the SB weather regime group consisting of the SB NAE-CWR and the eleven associated and ranked GWL regimes 
the Scandinavian block (Fig. 12), resulting in an "early NAO -" resembling MJO teleconnection pattern. In general, the patterns for other GWL regimes in the SB weather regime group are weak.

As highlighted before, although the eleven GWL regimes are matched to the SB weather regime group, the regimes may be distinctly different based on spatial anomaly patterns. It is thus unsurprising that there also exists substantial diversity in the MJO teleconnection patterns. We have shown here that it is useful to consider the SB NAE-CWR split into different types of Scandinavian block and assess the MJO influence on their frequency individually, over analysing teleconnections to the more general, large-scale NAE-CWR.

\section{Preferred transition pathways and changes in regime persistence}

Our analyses have suggested that some GWL regimes naturally occur during the transition stages between the large-scale NAE-CWRs, and that the MJO may modulate these preferred transition pathways. Using a similar method to compute the GWL regime transition matrix in James (2007), we compute the full transition distribution between GWL regimes, aimed to identify the preferred transition pathways of GWL regimes. Some GWL regimes may be more likely to develop into specific GWL regimes; other GWL regimes may show no strong preference between the transitions. The full transition distribution is calculated for all $29 \mathrm{GWL}$ regimes. This is achieved by calculating the number of 1-day transitions from a specific GWL regime to each of the other $28 \mathrm{GWL}$ regimes for all occurrences of the GWL regime (even if the present event lasts for only a day). Persistence of the GWL regime is represented by the 1-day transition from a specific GWL regime to itself. Percentage values are used to represent the statistical transition probabilities (Table S1). Using the leading percentage match excluding persistence, the primary transition is identified for all $29 \mathrm{GWL}$ regimes, illustrated in the primary transition schematic (Fig. 13).

WS and SZ (both in the NAO- weather regime group) primarily transit to SWZ (NAO+ weather regime group), and SWZ primarily transits to $\mathrm{WZ}(\mathrm{NAO}+$ weather regime group). Additionally, SWZ often follows from the transitions of GWL regimes in the NAO- weather regime group (Table S1). Similarly, for HNFA (SB weather regime group), it primarily transitions into $\mathrm{HNA}(\mathrm{NAO}-$ weather regime group), often transitioning to other GWL regimes in the NAO- weather regime group otherwise (Table S1).These
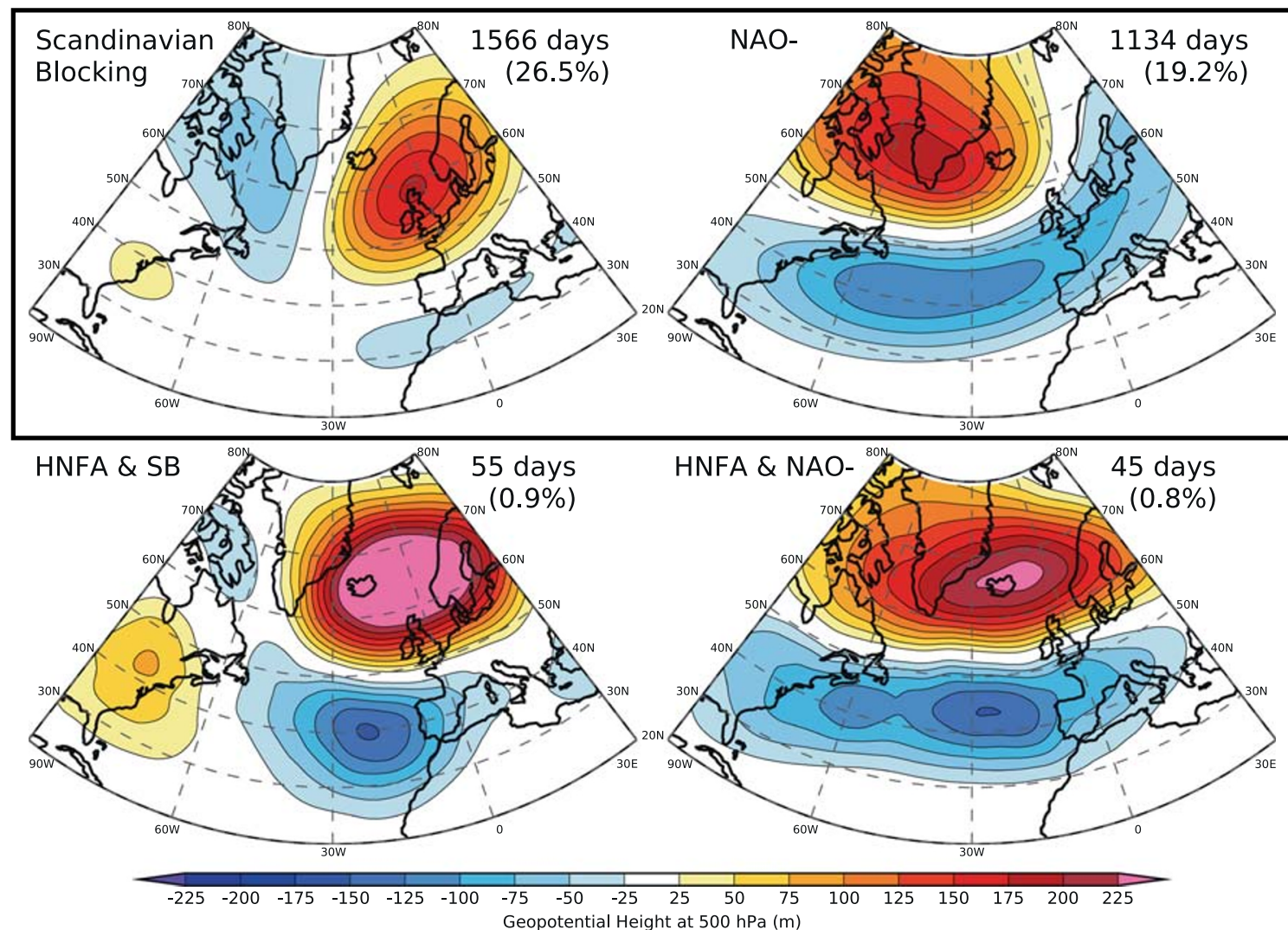

Fig. 12 As in Fig. 6, but for HNFA composited only for days when the NAE large-scale circulation patterns also correspond to SB NAE-CWR (bottom left) and NAO- NAE-CWR (bottom right) respectively. The spatial anomaly patterns for SB and NAO- NAE-CWRs are replicated above from Figs. 1 and 4, for comparison 


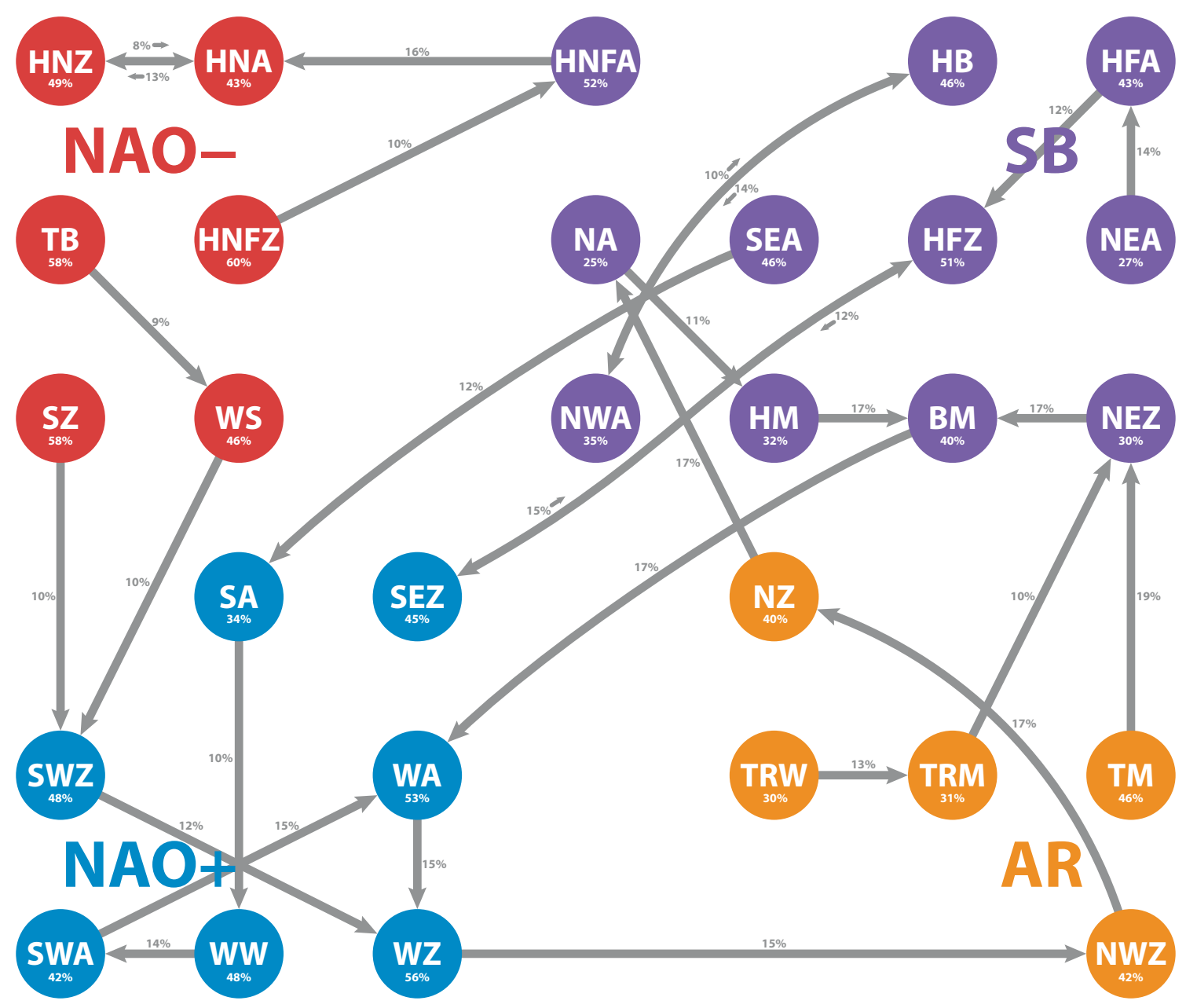

Fig. 13 Schematic diagram showing the primary transitions between the 29 GWL regimes. The diagram is based on climatological 1-day transitions during the extended boreal winter. The values from Table S1 are used to find the primary transition using the percentage majority, apart from persistence which is indicated below the GWL regimes. The arrows

results support the hypotheses that SWZ often occurs prior to GWL regimes in the NAO+ weather regime group and HNFA often occurs prior to GWL regimes in the NAO- weather regime group (Sections 3 and 4). Although not highlighted, these can also be qualitatively observed in James (2007).

The MJO teleconnection patterns from previous sections indicate that the preferred transition pathways, and hence full transition distributions, may be altered for certain phases. We extend the analyses to consider how the climatological transitions (Fig. 13) are modulated by the MJO, shown in Fig. 14. In this analysis, the sample size from the dataset is extremely small because the total number of 1-day transitions from each GWL is further split into nine MJO phases, including phase 0 . The changes in percentage values may be extreme and may result in changes in primary transitions. Nevertheless, the changes in percentage values are explored, with their significance tested using the binomial test at the $95 \%$ confidence level (Tables S2). The method used for computing the full (grey) represent the primary transition, along with the associated transition probability. The coloured circles represent the weather regime groups that a GWL regime belongs to the following: $\mathrm{NAO}^{-}$(red), $\mathrm{NAO}+$ (blue), AR (orange), SB (purple)

transition distribution for climatology is applied to the nine MJO phases, including phase 0 , focusing on the 1-day transitions 10-14 days after an MJO event. To increase the sample size, the mean of the transition matrices for lag 10-14 days are taken for each MJO phase (Tables S2). The number of days in which the changes in percentage values are significant at the 95\% confidence level is indicated in brackets (e.g. significant for 4 out of 5 days is indicated by " $4 / 5$ days").

There are certain significant changes in percentage values in the transition matrices. From the comparison of the transition matrices, WS is more likely to transition to SWZ 10 14 days after phase 1 . There are increased percentage values compared with climatology (4/5 days). These are captured by an increase in the probability from 10.0 to $32.0 \%$ (Tables S1 and S2) and could partly explain the increased frequency of SWZ 10-14 days after phase 1 (Fig. 7). Since SWZ is a climatological precursor to GWL regimes in the $\mathrm{NAO}+$ weather regime group, the results indicate that the state of the 


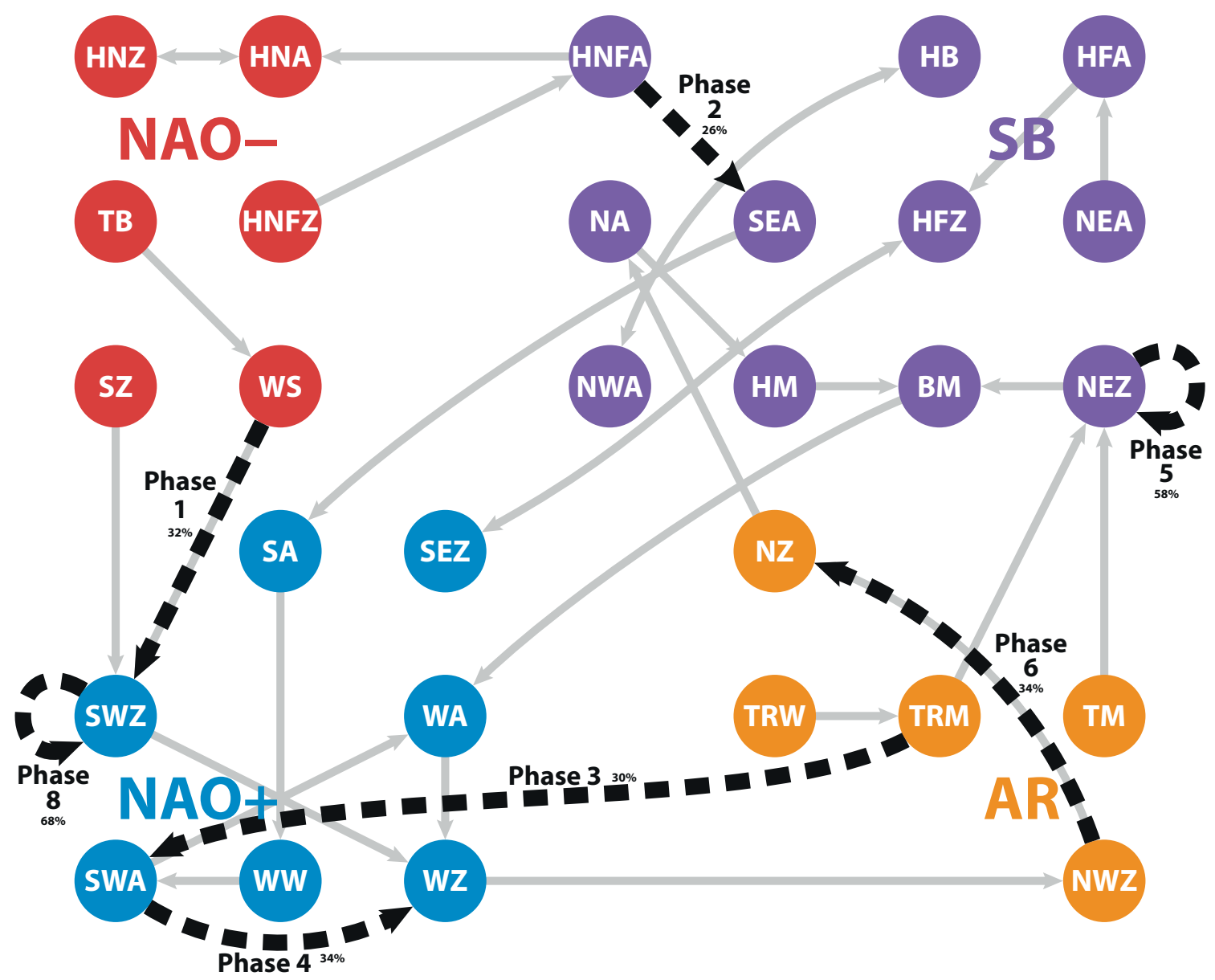

Fig. 14 As in Fig. 13, with additional dotted arrows (black) denoting the modulation of primary transitions or persistence by the MJO. The values from Tables S2 are used to find the primary transition using the percentage majority apart from persistence 10-14 days after MJO events

atmosphere often evolves to resemble the preferred precursors for the NAO+ NAE-CWR following phase 1 .

The reason for the increased frequency of SEA 10-14 days after phase 2 (Fig. 11) is explored next. Ten to fourteen days after phase 2, the probability of transitioning from HNFA to SEA increases from 3.0 to $25.8 \%$, with increased percentage values compared with climatology ( $5 / 5$ days). The spatial anomaly patterns for the transition from HNFA to SEA indicate a clockwise shift in the dipole anomaly pattern (Fig. 4) instead of the climatological anti-clockwise shift in the dipole anomaly pattern during the westward retrogression of the Scandinavian block associated with the preferred transition from HNFA to GWL regimes in the NAO- weather regime group. Hence, the excitation of the transition from HNFA to SEA for phase 2 is associated with the increased frequency. This may also be partially related to the reduction in frequencies of GWL regimes in the NAO- weather regime group 1014 days after phase 2 .

Phase 3 excites the transition of TRM to SWA. There are increased percentage values compared with climatology (4/5 days). These are captured by an increase in the probability from 5.0 to $29.1 \%$. This may partially explain the increased frequency of SWA 10-14 days after phase 3. Following the preferred internal transitions within the $\mathrm{NAO}+$ weather regime group from SWA, the frequencies of other GWL regimes within the group are also increased. It is surprising that the changes in percentage values are largely significant, given that TRM and SWA spatial anomaly patterns differ substantially. Further analysis of spatial anomaly patterns a few days prior and after the 1-day transition from TRM to SWA indicates an eastward progression of the ridge in the TRM spatial anomaly pattern, along with a trough that develops in the northwest, yielding the SWA spatial anomaly pattern (not shown).

Phase 4 excites the transition of SWA to WZ. There are increased percentage values compared with climatology (4/5 days). SWA often precedes WZ (even though it is not the primary transition), with a climatological transition probability of $14.3 \%$; this is increased to $34.2 \%$. This may explain the teleconnection patterns for SWA and WZ for phase 4. There are no increases in frequency of SWA at lag 10 
14 days because it quickly transitions to $\mathrm{WZ}$, resulting in an increased frequency for WZ instead.

Phase 6 excites the transition of NWZ to NZ. There are increased percentage values compared with climatology (3/5 days). These are captured by an increase in the probability from 17.2 to $34.4 \%$. Interestingly, $\mathrm{NZ}$ is a climatological successor of NWZ, analogous to successor 2 of the AR NAECWR from Vautard (1990), and links to the increased frequency of NZ at lag 10-14 days.

In addition to the climatological transitions, we investigate the modulation of the climatological persistence of GWL regimes by the MJO, using the same transition matrices. Ten to fourteen days after phase 5 , the persistence of NEZ increases from 30.0 to $58.4 \%$ (5/5 days). Similarly, 10-14 days after phase 8 , the persistence of SWZ increases from 47.5 to $68.1 \%$ (5/5 days). Interestingly, the spatial anomaly patterns for SWZ and NEZ appear to be similar yet opposite to each other, associated with strong negative/positive anomalies respectively stretching over the Eastern North Atlantic into the Scandinavian region, with weak positive/negative anomalies respectively over Greenland and Central Europe. This is likely related to other factors in addition to the contrasting influence of phases 5 and 8 . Further analysis of spatial anomaly patterns a few days prior to, and after, the occurrences of NEZ 1014 days lagged from phase 5 indicates a near-stationary development and then decay of the region of blocking. This region extends over the North Atlantic into the Scandinavian region (not shown), similar to the increased blocking frequency pattern over the region 15 days after MJO phase 6 , discussed in Henderson et al. (2016). Similar analysis for SWZ reveals the preferred evolution of the anomaly pattern from resembling the NAO- NAE-CWR to the NAO+ NAECWR (Fig. 9), associated with the decay of positive anomalies over Greenland and Iceland, and development of positive anomalies over Central Europe, with a near-stationary strong negative anomaly extending over the Eastern North Atlantic into the Scandinavian region (not shown). Considering that SWZ is analogous to a "developing NAO+", this appears dynamically consistent with the zonal wind tendencies independent of RWB shown in Swenson and Straus (2017).

The finer teleconnection details for some GWL regimes observed at lag 10-14 days for certain phases may be explained by increased precursor or successor probabilities, or persistence of related GWL regimes. These increased probabilities may be closely related to the increased likelihood of CWB or AWB events, especially following MJO phases 1, 2 and 3.

\section{Conclusion}

The Grosswetterlagen (GWL) is a useful set of 29 European weather regimes which can describe the synoptic scale flow patterns over the North Atlantic-European (NAE) region. In this study, we show how these GWL regimes can be modulated by teleconnection from the Madden-Julian Oscillation (MJO). We match these GWL regimes to four classical weather regimes (NAE-CWRs) that capture the large-scale flow characteristics over the NAE region and are useful for relating the GWL teleconnections to previous studies. We compute the patterns for the NAE-CWRs, in agreement with previous studies (Cassou 2008; Lin et al. 2009; Henderson et al. 2016). We also analyse the modulation of transitions between, and persistence of, GWL regimes associated with the MJO. Finer teleconnection details associated with the MJO are revealed in the GWL over the NAE-CWRs.

1) Some GWL regimes exhibit the expected MJO teleconnection patterns. For SWA, WZ and WA (associated with the NAO+ NAE-CWR), their frequencies are significantly increased by $\sim 50 \%, \sim 50 \%$ and $\sim 75 \%$ respectively, while the frequencies of WZ and WA are both significantly reduced by $\sim 50 \% \quad 10-15$ days after MJO phases 3 and 6 . The probability of transitioning from TRM (associated with the AR NAE-CWR) to SWA is significantly increased from 5.0 to $29.1 \%$ 10-14 days after phase 3 . This may explain the increased frequencies of GWL regimes in the NAO+ weather regime group following preferred internal transitions from SWA. HNZ and TB (associated with the NAO- NAE-CWR) also exhibit the expected pattern; the frequencies of HNZ and TB are both significantly increased by $\sim 75 \%$ and significantly reduced by $\sim 60 \%$ and $\sim 80 \%$ respectively, 10-15 days after MJO phases 7 and 3 occur. These GWL regimes exhibit similar teleconnection patterns to their associated NAE-CWR; their changes in occurrence probabilities are likely related to MJO-induced changes in the persistence and transition probabilities.

2) Some GWL regimes do not exhibit the expected MJO teleconnection patterns. There are only marginal and insignificant changes in the frequency of HNA (associated with the NAO- NAE-CWR) and WW (associated with the NAO+ NAE-CWR) for their corresponding MJO phases. We note the importance of considering the flow over Central Europe in determining the MJO teleconnection patterns; the presence of a weak ridge over Central Europe in HNA is absent in HNZ and TB. Likewise, the absence of a strong ridge over Central Europe in WW is present in SWA, WZ and WA. Both HNA and WW are not typical of their associated NAECWR here.

3) Other GWL regimes exhibit MJO teleconnection patterns between two main NAE-CWR teleconnections, explained by the crossed appearance of the two corresponding spatial anomaly patterns. Their occurrence may be related to the transition stages between NAE-CWRs. SWZ 
(associated with the NAO+ NAE-CWR) exhibits teleconnection patterns characteristic of both the $\mathrm{NAO}-$ and NAO+ NAE-CWRs; its frequency is significantly increased for phases 1,2,7 and 8. This may be associated with the significant increase in probability of transitioning from WS (associated with the NAO- NAE-CWR) to SWZ, from 10.0 to $32.0 \%, 10$ 14 days after phase 1 . Following the phase progression of the MJO, we hypothesise that SWZ is more likely to occur prior to, rather than after, GWL regimes in the $\mathrm{NAO}+$ weather regime group. Similarly, HNFA (associated with the SB NAECWR) exhibits teleconnection patterns characteristic of both the SB and NAO- NAE-CWRs. The frequency of HNFA is significantly increased by $\sim 120 \% 9$ 13 days after phase 5 . The shift in increased frequencies as the MJO progresses from phases 5 to 7 is characteristic of the teleconnection pattern for the NAO- NAE-CWR, shifted one phase earlier. Given this, we hypothesise that HNFA could be identified as an important intermediate GWL regime between the $\mathrm{SB}$ and NAO- weather regime groups, via westward retrogression. The opposite is observed 10-14 days after phase 2; a preferred clockwise shift in the dipole anomaly pattern instead of the climatological anticlockwise shift in the dipole anomaly pattern during the westward retrogression of the Scandinavian block occurs, captured by the significant increase in probability of transitioning from HNFA (associated with the NAO- NAE-CWR) to SEA from 3.0 to $25.8 \%$. This could explain the reduction in frequencies of GWL regimes in the $\mathrm{NAO}^{-}$weather regime group 10 14 days after phase 2 , since there is a preferred shift in the state of the atmosphere to resemble the precursors for the NAO+ NAE-CWR instead, possibly due to AWB events.

To further isolate any MJO influence, other confounding factors could also be considered. Phenomena such as El Niño-Southern Oscillation or sudden stratospheric warming events may also influence the frequency of NAE-CWRs (Lee et al. 2019) and GWL regimes. Nevertheless, these findings highlight the importance of the MJO for sub-seasonal predictions over the NAE region. Improved skill can be expected to be mediated by the prediction of weather regimes over the NAE region, which is particularly useful for end-users in various sectors to make cost-effective decisions with sufficient lead time.

Acknowledgments We thank the European Centre for Medium Range Weather Forecasting (ECMWF) for use of the ECMWF Interim Reanalysis (ERA-Interim) data, obtained from the ECMWF data server, and we thank Matthew Wheeler for the Madden-Julian Oscillation index (RMMI), available from http://poama.bom.gov.au/project/maproom/ $\mathrm{RMM} /$ createdPCs.TotAnom.74toRealtime.txt. We thank the two reviewers for their constructive and helpful comments.

Funding information JCKL was supported by the National Environment Agency, Singapore, and would like to thank the staff at Centre for Climate Research Singapore for their valuable feedback. The contribution from RWL is part of the InterDec project, funded by NERC grant NE/P006787/ 1 under the 2015 Joint Programming Initiative (JPI) Climate - Belmont Forum call. SJW was supported by the National Centre for Atmospheric Science, a Natural Environment Research Council collaborative centre under Contract R8/H12/83/001.

Open Access This article is licensed under a Creative Commons Attribution 4.0 International License, which permits use, sharing, adaptation, distribution and reproduction in any medium or format, as long as you give appropriate credit to the original author(s) and the source, provide a link to the Creative Commons licence, and indicate if changes were made. The images or other third party material in this article are included in the article's Creative Commons licence, unless indicated otherwise in a credit line to the material. If material is not included in the article's Creative Commons licence and your intended use is not permitted by statutory regulation or exceeds the permitted use, you will need to obtain permission directly from the copyright holder. To view a copy of this licence, visit http://creativecommons.org/licenses/by/4.0/.

\section{References}

Baur F, Hess P, Nagel H (1944) Kalendar der Grosswetterlagen Europas 1881-1939. Bad Homburg (DWD)

Benedict JJ, Lee S, Feldstein SB (2004) Synoptic view of the North Atlantic oscillation. J Atmos Sci 61(2):121-144. https://doi.org/10. 1175/1520-0469(2004)061<0121:SVOTNA >2.0.CO;2

Bloomfield HC, Brayshaw DJ, Shaffrey LC, Coker PJ, Thornton HE (2016) Quantifying the increasing sensitivity of power systems to climate variability. Environ Res Lett 11(12):124025. https://doi.org/ 10.1088/1748-9326/11/12/124025

Cannon D, Brayshaw D, Methven J, Drew D (2017) Determining the bounds of skilful forecast range for probabilistic prediction of system-wide wind power generation. Meteorol Z 26(3):239-252. https://doi.org/10.1127/metz/2016/0751

Casanueva VA, Rodríguez Puebla C, Frías Domínguez MD, González Reviriego N (2014) Variability of extreme precipitation over Europe and its relationships with teleconnection patterns. Hydrol Earth Syst Sci 18(2):709-725. https://doi.org/10.5194/hess-18-709-2014

Cassou C (2008) Intraseasonal interaction between the Madden-Julian oscillation and the North Atlantic oscillation. Nature 455(7212): 523-527. https://doi.org/10.1038/nature07286

Charlton-Perez AJ, Ferranti L, Lee RW (2018) The influence of the stratospheric state on North Atlantic weather regimes. Quart J Roy Meteor Soc 144 (713):1140-1151. https://doi.org/10.1002/qj.3280

Cheng X, Wallace JM (1993) Cluster analysis of the Northern Hemisphere wintertime 500-hPa height field: spatial patterns. J Atmos Sci 50(16):2674-2696. https://doi.org/10.1175/15200469(1993)050<2674:CAOTNH >2.0.CO;2

Dee DP, Uppala SM, Simmons AJ, Berrisford P, Poli P, Kobayashi S, Andrae U, Balmaseda MA, Balsamo G, Bauer P, Bechtold P, Beljaars ACM, van de Berg L, Bidlot J, Bormann N, Delsol C, Dragani R, Fuentes M, Geer AJ, Haimberger L, Healy SB, Hersbach H, Hólm EV, Isaksen L, Kållberg P, Köhler M, 
Matricardi M, McNally AP, Monge-Sanz BM, Morcrette JJ, Park BK, Peubey C, de Rosnay P, Tavolato C, Thépaut JN, Vitart F (2011) The ERA-Interim reanalysis: configuration and performance of the data assimilation system. Quart J Roy Meteor Soc 137(656): 553-597. https://doi.org/10.1002/qj.828

Ferranti L, Palmer TN, Molteni F, Klinker E (1990) Tropical-extratropical interaction associated with the 30-60 day oscillation and its impact on medium and extended range prediction. J Atmos Sci 47(18): 2177-2199. https://doi.org/10.1175/1520-0469(1990)047<2177: TEIAWT>2.0.CO;2

Garfinkel CI, Benedict JJ, Maloney ED (2014) Impact of the MJO on the boreal winter extratropical circulation. Geophys Res Lett 41:60556062. https://doi.org/10.1002/2014GL061094

Gerstengabe FW, Werner PC, Rüge U (1999) Katalog der Grosswetterlagen Europas 1881-1998 nach P. Hess und H. Brezowsky. Potsdam-Inst. F. Klimafolgenforschung, Potsdam, 138 pp.

Gottschalck J, Wheeler M, Weickmann K, Vitart F, Savage N, Lin H, Hendon H, Waliser D, Sperber K, Nakagawa M, Prestrelo C (2010) A framework for assessing operational Madden-Julian oscillation forecasts: a CLIVAR MJO working group project. Bull Amer Meteor Soc 91(9):1247-1258. https://doi.org/10.1175/ 2010BAMS2816.1

Grams CM, Beerli R, Pfenninger S, Staffell I, Wernli H (2017) Balancing Europe's wind-power output through spatial deployment informed by weather regimes. Nat Clim Chang 7(8):557. https://doi.org/10. 1038/nclimate 3338

Heide D, Von Bremen L, Greiner M, Hoffmann C, Speckmann M, Bofinger S (2010) Seasonal optimal mix of wind and solar power in a future, highly renewable Europe. Renew Energy 35(11):24832489. https://doi.org/10.1016/j.renene.2010.03.012

Henderson SA, Maloney ED, Barnes EA (2016) The influence of the Madden-Julian oscillation on Northern Hemisphere winter blocking. J Clim 29(12):4597-4616. https://doi.org/10.1175/JCLID-15-0502.1

Hess P, Brezowsky H (1952) Katalog der Grosswetterlagen Europas. Berichte des Deutschen Wetterdienstes in der US-Zone 33

Hess P, Brezowsky H (1969) Katalog der Grosswetterlagen Europas, 2. neu bearbeitete und ergänzte Aufl. Berichte des Deutschen Wetterdienstes 113. Offenbach am Main

Hess P, Brezowsky H (1977) Katalog der Grosswetterlagen Europas 1881-1976, 3. verbesserte und ergänzte Aufl. Berichte des Deutschen Wetterdienstes 113. Offenbach am Main

Hoskins BJ, Ambrizzi T (1993) Rossby wave propagation on a realistic longitudinally varying flow. J Atmos Sci 50(12):1661-1671. https:// doi.org/10.1175/1520-0469(1993)050<1661:RWPOAR>2.0.CO;2

Hoskins BJ, Karoly DJ (1981) The steady linear response of a spherical atmosphere to thermal and orographic forcing. J Atmos Sci 38(6): 1179-1196. https://doi.org/10.1175/1520-0469(1981)038<1179: TSLROA $>2.0 . \mathrm{CO} ; 2$

Hurrell JW (1995) Decadal trends in the North Atlantic oscillation: regional temperatures and precipitation. Science. 269(5224):676-679. https://doi.org/10.1126/science.269.5224.676

James PM (2007) An objective classification method for Hess and Brezowsky Grosswetterlagen over Europe. Theor Appl Climatol 88(1-2):17-42. https://doi.org/10.1007/s00704-006-0239-3

Jones C (2000) Occurrence of extreme precipitation events in California and relationships with the Madden-Julian oscillation. J Clim 13(20): 3576-3587. https://doi.org/10.1175/1520-0442(2000)013<3576: OOEPEI $>2.0 . \mathrm{CO} ; 2$

Kiladis GN, Weickmann KM (1992) Circulation anomalies associated with tropical convection during northern winter. Mon Weather Rev 120(9):1900-1923. https://doi.org/10.1175/1520-0493(1992) 120<1900:CAAWTC $>2.0 . \mathrm{CO} ; 2$
Kirilenko AP, Sedjo RA (2007) Climate change impacts on forestry. Proc Natl Acad Sci 104(50):19697-19702. https://doi.org/10.1073/pnas. 0701424104

Lavalle C, Micale F, Houston TD, Camia A, Hiederer R, Lazar C, Conte C, Amatulli G, Genovese G (2009) Climate change in Europe. 3. Impact on agriculture and forestry. A review. Agron Sustain Dev 29(3):433-446. https://doi.org/10.1051/agro/2008068

Lee RW, Woolnough SJ, Charlton-Perez AJ, Vitart F (2019) ENSO modulation of MJO teleconnections to the North Atlantic and Europe. Geophys Res Lett 46(22):13535-13545. https://doi.org/10.1029/ 2019GL084683

Lin H, Brunet G, Derome J (2008) Forecast skill of the Madden-Julian oscillation in two Canadian atmospheric models. Mon Weather Rev. 136:4130-4149. https://doi.org/10.1175/2008MWR2459.1

Lin H, Brunet G, Derome J (2009) An observed connection between the North Atlantic oscillation and the Madden-Julian oscillation. J Clim 22(2):364-380. https://doi.org/10.1175/2008JCLI2515.1

Maracchi G, Sirotenko O, Bindi M (2005) Impacts of present and future climate variability on agriculture and forestry in the temperate regions: Europe. Clim Chang 70(1-2):117-135. https://doi.org/10. 1007/s10584-005-5939-7

Masato G, Hoskins BJ, Woollings TJ (2012) Wave-breaking characteristics of midlatitude blocking. Quart J Roy Meteor Soc 138(666): 1285-1296. https://doi.org/10.1002/qj.990

Matsueda S, Takaya Y (2015) The global influence of the Madden-Julian oscillation on extreme temperature events. J Clim 28(10):41414151. https://doi.org/10.1175/JCLI-D-14-00625.1

Matthews AJ, Hoskins BJ, Masutani M (2004) The global response to tropical heating in the Madden-Julian oscillation during the northern winter. Quart J Roy Meteor Soc 130(601):1991-2011. https://doi. org/10.1256/qj.02.123

Michelangeli PA, Vautard R, Legras B (1995) Weather regimes: recurrence and quasi stationarity. J Atmos Sci 52(8):1237-1256. https:// doi.org/10.1175/1520-0469(1995)052<1237:WRRAQS >2.0.CO;2

Mori M, Watanabe M (2008) The growth and triggering mechanisms of the PNA: a MJO-PNA coherence. J Meteor Soc Japan Ser II 86(1): 213-236. https://doi.org/10.2151/jmsj.86.213

Neal R, Fereday D, Crocker R, Comer RE (2016) A flexible approach to defining weather patterns and their application in weather forecasting over Europe. Meteor Appl 23(3):389-400. https://doi.org/10. 1002/met.1563

Plaut G, Simonnet E (2001) Large-scale circulation classification, weather regimes, and local climate over France, the Alps and Western Europe. Clim Res 17(3):303-324. https://doi.org/10.3354/cr017303

Reinhold BB, Pierrehumbert RT (1982) Dynamics of weather regimes: quasi-stationary waves and blocking. Mon Weather Rev. 110(9): 1105-1145. https://doi.org/10.1175/1520-0493(1982)110<1105: DOWRQS $>2.0 . \mathrm{CO} ; 2$

Rivière G, Orlanski I (2007) Characteristics of the Atlantic storm-track eddy activity and its relation with the North Atlantic oscillation. J Atmos Sci 64(2):241-266. https://doi.org/10.1175/JAS3850.1

Santos JA, Corte-Real J, Leite SM (2005) Weather regimes and their connection to the winter rainfall in Portugal. Int J Climatol 25(1): 33-50. https://doi.org/10.1002/joc.1101

Santos-Alamillos FJ, Brayshaw DJ, Methven J, Thomaidis NS, RuizArias JA, Pozo-Vázquez D (2017) Exploring the meteorological potential for planning a high performance European electricity super-grid: optimal power capacity distribution among countries. Environ Res Lett 12(11):114030. https://doi.org/10.1088/17489326/aa $8 \mathrm{f} 18$

Sardeshmukh PD, Hoskins BJ (1988) The generation of global rotational flow by steady idealized tropical divergence. J Atmos Sci 45(7): 1228-1251. https://doi.org/10.1175/1520-0469(1988)045<1228: TGOGRF $>2.0 . \mathrm{CO} ; 2$

Scheifinger H, Menzel A, Koch E, Peter C (2003) Trends of spring time frost events and phenological dates in Central Europe. Theor Appl 
Climatol 74(1-2):41-51. https://doi.org/10.1007/s00704-002-0704-

Smyth P, Ide K, Ghil M (1999) Multiple regimes in northern hemisphere height fields via MixtureModel clustering. J Atmos Sci 56(21): 3704-3723. https://doi.org/10.1175/1520-0469(1999)056<3704: MRINHH $>2.0 . \mathrm{CO} ; 2$

Soares MB, Alexander M, Dessai S (2018) Sectoral use of climate information in Europe: a synoptic overview. Climate Serv 9:5-20. https:// doi.org/10.1016/j.cliser.2017.06.001

Stan C, Straus DM, Frederiksen JS, Lin H, Maloney ED, Schumacher C (2017) Review of tropical-extratropical teleconnections on intraseasonal time scales. Rev Geophys 55(4):902-937. https://doi. org/10.1002/2016RG000538

Swenson ET, Straus DM (2017) Rossby wave breaking and transient eddy forcing during Euro-Atlantic circulation regimes. J Atmos Sci 74(6):1735-1755. https://doi.org/10.1175/JAS-D-16-0263.1

Thorncroft CD, Hoskins BJ, McIntyre ME (1993) Two paradigms of baroclinic-wave life-cycle behaviour. Quart J Roy Meteor Soc 119(509):17-55. https://doi.org/10.1002/qj.49711950903

Ullmann A, Fontaine B, Roucou P (2014) Euro-Atlantic weather regimes and Mediterranean rainfall patterns: present-day variability and expected changes under CMIP5 projections. Int J Climatol 34(8): 2634-2650. https://doi.org/10.1002/joc.3864

Vallis GK, Gerber EP (2008) Local and hemispheric dynamics of the North Atlantic oscillation, annular patterns and the zonal index. Dyn Atmos Oceans 44(3-4):184-212. https://doi.org/10.1016/j. dynatmoce.2007.04.003

Vautard R (1990) Multiple weather regimes over the North Atlantic: analysis of precursors and successors. Mon Weather Rev. 118(10):
2056-2081. https://doi.org/10.1175/1520-0493(1990)118<2056: MWROTN $>2.0 . \mathrm{CO} ; 2$

Vecchi GA, Bond NA (2004) The Madden-Julian oscillation (MJO) and northern high latitude wintertime surface air temperatures. Geophys Res Lett 31(4). https://doi.org/10.1029/2003GL018645

Vitart F (2014) Evolution of ECMWF sub-seasonal forecast skill scores. Quart J Roy Meteor Soc 140(683):1889-1899. https://doi.org/10. 1002/qj.2256

Wheeler MC, Hendon HH (2004) An all-season real-time multivariate MJO index: development of an index for monitoring and prediction. Mon Weather Rev 132(8):1917-1932. https://doi.org/10.1175/ 1520-0493(2004)132<1917:AARMMI>2.0.CO;2

Woollings T, Hoskins B, Blackburn M, Berrisford P (2008) A new Rossby wave-breaking interpretation of the North Atlantic oscillation. J Atmos Sci 65(2):609-626. https://doi.org/10.1175/ 2007JAS2347.1

Yadav P, Straus DM (2017) Circulation response to fast and slow MJO episodes. Mon Weather Rev. 145(5):1577-1596. https://doi.org/10. 1175/MWR-D-16-0352.1

Yiou P, Goubanova K, Li ZX, Nogaj M (2008) Weather regime dependence of extreme value statistics for summer temperature and precipitation. Nonlinear Process Geophys Eur Geophys Union (EGU) 15(3):365-378. https://doi.org/10.5194/npg-15-365-2008

Publisher's note Springer Nature remains neutral with regard to jurisdictional claims in published maps and institutional affiliations. 